To cite this article: José David Cisneros-Martínez, Scott McCabe \& Antonio FernándezMorales (2017): The contribution of social tourism to sustainable tourism: a case study of seasonally adjusted programmes in Spain, Journal of Sustainable Tourism, DOI:

10.1080/09669582.2017.1319844

\title{
The contribution of social tourism to sustainable tourism: a case study of seasonally adjusted programmes in Spain
}

\begin{abstract}
Recent policy from the European Union has attempted to justify social tourism initiatives on the basis that they lead to a more sustainable tourism industry. However, the majority of latest research in the field has been focused on the benefits for participants, with the addition of some evidence on the economic impacts of such programmes on destinations, which have pointed towards sustainability outcomes including: a longer tourism season, more even spread of demand, and longer periods of employment for tourism workers. Yet there is a lack of direct evidence linking such programme to these outcomes. This paper aimed to explore this important disconnect between policy assumptions and evidence-based outcomes through an analysis of the deseasonalising effects of the Spanish social tourism programme for older people. The research found that this programme does have an effect on the seasonal nature of employment and economic activity in most regions studied, but that the huge volume of demand from international tourists in the high seasons masks the quantitative effects in the regions with the highest seasonal concentration of international tourists. Recommendations for policy and practice in sustainable tourism are made that are transferable to many countries and regions that adopt social tourism programmes.
\end{abstract}

Keywords: social tourism; Gini index; seasonality; relative marginal effect; IMSERSO; Spain

\section{Introduction}

Recent policy initiatives on social tourism emanating from the European Commission have highlighted the positive contribution that this form of tourism can broadly make towards a more sustainable tourism (European Economic and Social Committee, 2006). Indeed, in a review of the development of EU policy, which saw the integration of social tourism into the main framework programme for sustainable tourism, Diekmann and McCabe (2011) highlighted a major shift in emphasis from an orientation to social inclusiveness and equality of opportunity, towards a greater focus on economic sustainability. The main arguments for linking social tourism to sustainability aspirations lies in the potential it delivers for off-season tourism activity, smoothing out some of the main problems associated with highly seasonal demand patterns. As the following quote from the European Commission (EC) demonstrates, economic sustainability is a key rationale behind social tourism policy: "In promoting access for groups for which going on holiday has progressively become more difficult, social tourism strengthens the tourism industry's revenue generation potential. Social tourism aids mobility and enables off-season tourism to be developed, particularly in regions where tourism is highly seasonal. Accordingly, social tourism encourages the creation of longer-lasting employment 
opportunities in the tourism sector, in line with the Lisbon Strategy, by making it possible to extend such jobs beyond the respective peak season." (as cited in Diekmann and McCabe, 2013, p. 24).

Seasonality can be considered one of the most important issues affecting sustainability in tourism. Seasonality in tourism is usually defined as the tendency of tourist flows to become concentrated in relatively short periods of the year (Allcock, 1994). This phenomenon is one of the biggest challenges faced by the tourism sector causing major problems such as; unstable employment, limits on the profitability of investments, mismatch in loading capacity, fluctuations in prices, environmental deterioration and, various sociocultural effects between visitors and residents. These issues of seasonality, its causes and effects have been widely discussed over many decades, and the purpose of this study is not to rehearse those debates. Indeed, several recent papers provide excellent reviews of these issues (cf. Coshall, Charlesworth, \& Page, 2015; Koenig-Lewis \& Bischoff, 2005). Typically, what research shows is that a high degree of seasonality of tourism demand can generate problems related to sustainability both in the peak season and in the low season. In this paper the focus is on the seasonality effects related to the problems derived from reduced demand in the low season. For example, one of the most important negative factors of seasonality is the impact on stability of employment. In Spain, alongside many comparable European Mediterranean holiday destinations, the considerable job losses sustained outside the high season have a significant social as well as economic impact on tourist areas. These impacts, due to labour instability and unemployment, have been widely described in several studies as the ones by Ashworth and Thomas (1999), Baum and Lundtorp (2001).

Tourism is the primary economic sector in Spain both in terms of the number of workers, with more than 2.1 million people employed, accounting for $11.9 \%$ of total employment (in the island regions this figure is around 25\%) and by turnover, representing $10.9 \%$ of Gross Domestic Product "Producto Interior Bruto (PIB), according to the latest Spanish Tourism Satellite Account (National Statistics Institute "Instituto Nacional de Estadística" [INE], 2014a). However, demand in the Spanish tourism sector is highly seasonal, which is concentrated generally in the months of July to September (INE, 2014b). It suffers a loss of up to $54 \%$ of all jobs at the end of each summer season in coastal destinations due to seasonal decline (INE, 2014a). For example, over 191,000 employees were recorded in the hospitality sector in August 2014 compared with 87,000 in January of the same year (INE, 2014c).

Thus, it is natural that the European Commission seeks to develop policy in tourism aimed at tackling this important issue. Indeed, the EC based the Calypso programme for social tourism mainly on the economic benefits and the reduction of seasonality it offers. The Calypso initiative was implemented over the period 2009-2012 to enable the most disadvantaged citizens (young, elderly, disabled people and low-income families) to travel across Europe (eCalypso, 2016). Under this initiative, the EC has funded many projects facilitating holiday travel for disadvantaged groups with the aim of increasing tourism in the low season to help local economies combat seasonality through the creation of new jobs and business opportunities. These projects include: (1) European Senior Travellers (ETS): Promoting senior citizen exchanges between Portugal, Spain and Poland, (2) Social Tourism European 
Exchanges Platform (STEEP): Facilitating transnational tourism particularly during the low season, (3) Holiday 4all: Enhancing and promoting transnational cooperation in the Danube macro-region in social tourism development and (4) OFF2013: Facilitating low-season transnational exchanges of senior and families facing difficult circumstances in Hungary and Poland (European Commission, 2016). Although these programs have been implemented in several European countries, to date, there are no studies that have focused on measuring the deseasonalising impact of these initiatives.

Yet despite a recent proliferation of studies on social tourism, these almost exclusively focus on the demand side perspective, particularly on the personal and social benefits of social tourism schemes (McCabe \& Johnson, 2013; Minnaert, Maitland, \& Miller, 2009), with virtually no studies on the detailed contribution of such programmes towards achieving economic sustainability goals. The assessment of these economic impacts has been restricted to some qualitative studies by consultants together with some key quantitative analyses such as the one undertaken by PricewaterhouseCoopers (PwC) in the case of Spain (PwC, 2012). Furthermore, according to the Spanish Institute of Social Services and the Elderly "Instituto de Mayores y Servicios" (IMSERSO) the social tourism programme undertaken by this organisation helps to reduce seasonality (IMSERSO, 2014). However, there are no studies that have focused in detail on measuring the contribution that any of those programmes actually have on reducing seasonality. The present study seeks to address this gap to analyse whether there is, and if so, the quantitative contribution to the specific deseasonalising impact that overnight stays through IMSERSO supported trips have on the Spanish economy; assessing for the first time the claim of social tourism as a driver of economic sustainability. The study examines overnight accommodation data in 3- and 4-star hotels (categories of hotels in which beneficiaries of the IMSERSO trips stay) within mainland (and island) Spanish coastal destinations where the vast majority of these trips take place.

The problems of high seasonality in the Spanish coastal regions, especially in the summer period have been the subject of numerous studies as the recent one by Duro (2016), which have sought to evaluate these issues in the main provinces of Spain (including those analysed in this study). Other studies have focused on specific Spanish regions, confirming the high seasonality in the coastal provinces of Andalucía (Cisneros-Martínez \& Fernández-Morales, 2015), on the Comunidad Valenciana littoral (Yepes Piqueras, 2002), on Cataluña (Duro \& Turrión-Prats, 2015), on Islas Baleares (Capó Parrilla, Riera Font, \& Roselló Nadal, 2007) and on Islas Canarias (Gil-Alana, 2010). The destinations cannot overcome seasonality issues entirely through domestic policies and strategies, since demand is constrained by cultural vacation patterns in generating regions, in addition to external factors including seasonal weather conditions. In this regards, some authors like BarOn (1975), and Butler and Mao (1997) make a distinction between natural seasonality which is weather dependent, and institutional seasonality, based on cultural values. However, tourism development strategies can be deployed that offer the potential to mitigate seasonality effects, and social tourism has been promoted as one such strategy in Spain together with other European countries (http://www.europeseniortourism.eu). This paper aims to verify whether this is indeed an effective strategy in the case of IMSERSO supported tourist activity. 


\section{Social tourism and sustainability}

Social tourism and issues of sustainability can be linked to the development of mass tourism in Europe following the post WWII era. Although the development of both the social tourism and sustainability concept can be traced back much further to the beginnings of industrialisation processes (Baumgartner, 2011; Walton, 2013), it is not until the recognition of tourism's potential as an engine of economic growth that these issues came to the fore. Saarinen (2006) pointed to the negative environmental consequences of tourism development around Europe in the 1960's and 1970's as initiating a debate about limits to growth, carrying capacities and eventually the need for more sustainable forms of tourism after the Brundtland Report in 1987. The literature on sustainable tourism is highly critical about the prospects for both the concept and applicability of sustainable principles in tourism (e.g. Butler, 1999). Saarinen (2006) pointed to the problems of the scale of evaluation, the ethical and ideological nexus between global and local as being important sources of difference between sustainable development and sustainable tourism for example. Yet, the changes brought about by post-Fordist modes of production and consumption in tourism have resulted in the need for more sustainable tourism.

Mass democratisation of international travel inevitably led to issues of inclusiveness and equity in consumption of tourism as vulnerable groups are less able to participate. Social tourism is defined as "all activities, relationships and phenomena in the field of tourism resulting from the inclusion of otherwise disadvantaged and excluded groups in participation in tourism." (Minnaert, Diekmann, \& McCabe, 2012: 29). This type of tourism has become the focus for renewed research interest amongst the tourism academy in recent years; numerous papers have adequately defined and outlined the main issues relating to European social tourism (Minnaert, Maitland et al., 2011), including the shift from a more social rationale towards one based on economic and social sustainability (Diekmann \& McCabe, 2011).

Sustainable development at a destination level is usually based on the three pillars: environmental, socio-cultural and economic (Ayuso, 2003). As mass holiday destinations have become urbanised communities, including many residents, the need to consider the economic viability of destinations for the long-term has become critical. Therefore, the seasonality inherent in tourism includes several negative effects that could affect the sustainability of destinations, beyond the purely economic, but include social and environmental. Agawal and Brunt (2006) argued that English coastal resorts which had suffered from a lack of investment in tourism planning and development had led to high levels of deprivation in these communities, and although not ostensibly linked to the literature on sustainable development, their research clearly highlights the lack of a sustainable ethos as partly responsible.

Further issues arise in destinations experiencing very high tourism demand. High concentrations of visitors at certain times of the year mean that some destinations experience major impacts (Butler, 2001). Martín Martín, Jiménez Aguilera, and Molina Moreno, 2014) classified them as: environmental (overexploitation of natural resources and massive waste production), socio-cultural (loss of quality of life of residents and dissatisfaction of tourists) and economic (instability of employment, less competitiveness, and profitability difficulties in the long term). One of the strategies often used to reduce such impacts is to redistribute tourist 
flows throughout the year in an attempt to achieve a more balanced temporal distribution of demand.

In recent literature, several studies analysed seasonality to examine whether certain segments of demand can help mitigate the effects of seasonality either explicitly or implicitly linking such efforts to a more sustainable tourism. Examples include: the VFR, holiday and business segments in Scotland (Coshall, et al., 2015), and throughout the UK, specifically the English regions (Fernández-Morales, Cisneros-Martínez, \& McCabe, 2016); the events segment in Scotland (Connell, Page, \& Meyer, 2015); the cultural segment in Sicily (Cuccia \& Rizzo, 2011), the domestic segment in Scotland, focused in Wales (Koenig-Lewis \& Bischoff, 2003), and in Argentina (Cisneros-Martínez \& Fernández-Morales, 2016). In Spain, recent studies analysed the effectiveness of different segments for their deseasonalising effect, including; the cruise segment (Fernández-Morales \& Martín-Carrasco, 2015), the cultural segment (CisnerosMartínez \& Fernández-Morales, 2015) and the domestic and international segments (Halpern, 2011; Rosselló \& Sansó, 2017). However, as far as we know, the deseasonalising effect of social tourism programmes has not been assessed and quantified in the literature, which is a key aim of the current paper.

Social tourism is also linked to debates in sustainable tourism due to the fact it takes a more holistic approach relating to the ethics underpinning sustainable tourism, and for the ways in which it is framed as a more responsible form of tourism (Hall \& Brown, 1996), contrasted with the more morally circumspect practices of the global tourism industry. For example, HigginsDesbiolles (2006) argued that some forms of tourism, including social tourism can be considered more socially oriented since they are not profit driven; and thus more likely to consider the environment and local residents' views more favourably than the industry, often characterised by short-term, profit-driven interests. These characteristics are intrinsic to sustainable tourism values.

In addition, such forms of tourism are more sensitive to local issues. Indeed, Minnaert, Maitland et al. (2006) argued that social tourism can encompass host-related forms of activity, which include community-based and pro-poor initiatives. Often, social tourism is closely connected to the values and customs of local residents, and may therefore be considered a more sustainable form of tourism. Baumgartner (2011) addressed the question of whether there are any inherent differences in the concepts of social tourism and sustainable tourism, and specifically if sustainable tourism is the logical consequence of social tourism. Also, he traced social tourism to the early origins of mass tourism in Europe and argued that whilst sustainable tourism is a fairly recent term, the practices and characteristics of both types of tourism share many similarities and historical roots: they are both concerned with a desire to reduce social inequality, at the same time sharing a concern for minimising impacts on the environment; and crucially, that the economic benefits of tourism activity should be shared more equitably and distributed more widely in the system.

However, the greater emphasis of recent research has focused on the needs, experiences, and outcomes for tourists. Therefore, research has focused on the outcomes with less attention on the macro-level strategic and supply side perspectives. Much of the thrust of recent research 
has addressed social issues, such as wellbeing outcomes of tourists and/or residents as opposed to either the environmental or economic aspects of sustainability in social tourism. There are a few exceptions however. Eusébio, Carneiro, Kastenholz, and Alvelos (2016) conducted an analysis of the economic impacts of the Portuguese senior tourism programme, which shares many similarities with the Spanish case. They used a survey of stakeholders on their perceptions of the impacts of the programme alongside a quantitative analysis of the national data on the economic impacts of the INATEL programme on the national economy. Perceptions of stakeholders confirmed the national data, which showed positive outcomes on profitability, employment, hotel occupancy rates in the low season, and increased customer loyalty. However, there remains little detailed evidence on the effects of increasing the seasonal distribution of demand, and thus, the impact of social tourism on the economy and vitality of regions.

\subsection{Social tourism in Spain and the IMSERSO programme}

Social tourism activity in Spain is based mainly on IMSERSO trips for older citizens. These trips are organized and partially funded by the Spanish Ministry of Health, Social Policy and Equality 'Ministerio de Sanidad, Servicios Sociales e Igualdad' through the IMSERSO, which facilitates the human and technical resources for planning, monitoring and control of the programme (IMSERSO, 2014). The financing provided by the Spanish government in 2014 equated to $20.87 \%$ of the total cost of trip, the rest being paid by the beneficiaries themselves (IMSERSO, 2014). The IMSERSO budget amounted to a total of $66,322,423.45 €$ in the last season for which data is available (IMSERSO, 2015a).

Spain is a pioneer country in terms of senior tourism, whereas other countries/regions have focused on other segments (e.g. Poland, primarily the youth market; Flanders, persons living in poverty, disabled people, children/youth, low-income families and senior citizens). The Spanish model has also been adopted in Argentina and Chile (Nuñez \& Baison, 2007). The reasons why older people are not supported so much in other European countries are diverse, but may be due to high levels of pension provisions and other benefits, and a high preponderance amongst older people to be already active in holiday participation. Another consideration is that the IMSERSO, as opposed to other social tourism programmes, aims to reduce seasonality explicitly. Therefore, senior citizens are a logical target group as they tend to travel outside the peak season, and since they are mostly outside the labour market, have greater flexibility.

The senior segment, in general, has a very important growth perspective. As Kim, Woo, and Uysal (2015) claimed, the demographic evolution towards a more aged population will generate a greater proportion of senior tourists in the tourism market. Moreover, as other authors have maintained "today's senior market differs greatly from the stereotypical mould of senior tourists of past areas, and that it is a misunderstanding to think of senior citizens 55 years or older than weak, dependent, lonely, or physically or mentally limited, who want only consistency and predictability when they travel" (Chen \& Shoemaker, 2014, p. 60). In Spain, this market has a very considerable importance, since it is one of the European countries with a rapidly growing aging population, which are experienced in tourism, and in addition, it receives a high level of international demand from older tourists (Alén, Nicolau, Losada, \& Domínguez, 2014). In 
Spain, the IMSERSO programme has a great relevance amongst senior tourists whom it is estimated that $21 \%$ of all seniors-population over 55 in their study — opted for a trip from IMSERSO (Alén, Losada, and Domínguez 2016). The aim of the IMSERSO programme is to improve the quality of life of elderly people, enhancing economic activity in various sectors of the economy, and encourage the creation and maintenance of employment in the tourism sector during the low season. In addition, this programme has become an indispensable tool in the fight against seasonality in the tourism sector. The IMSERSO activity benefits both tourists and destinations. The number of overnight stays generated by the IMSERSO programme for the period 2007-2014, by region, is shown in Figure 1. As seen, there are several regions that have experienced a fall in the volume of demand. In this regard, Islas Canarias, Islas Baleares and Murcia show a decrease in the period of $34 \%, 24 \%$ and $16 \%$ respectively. In the remaining regions, the behaviour is quite erratic showing quite strong variation.

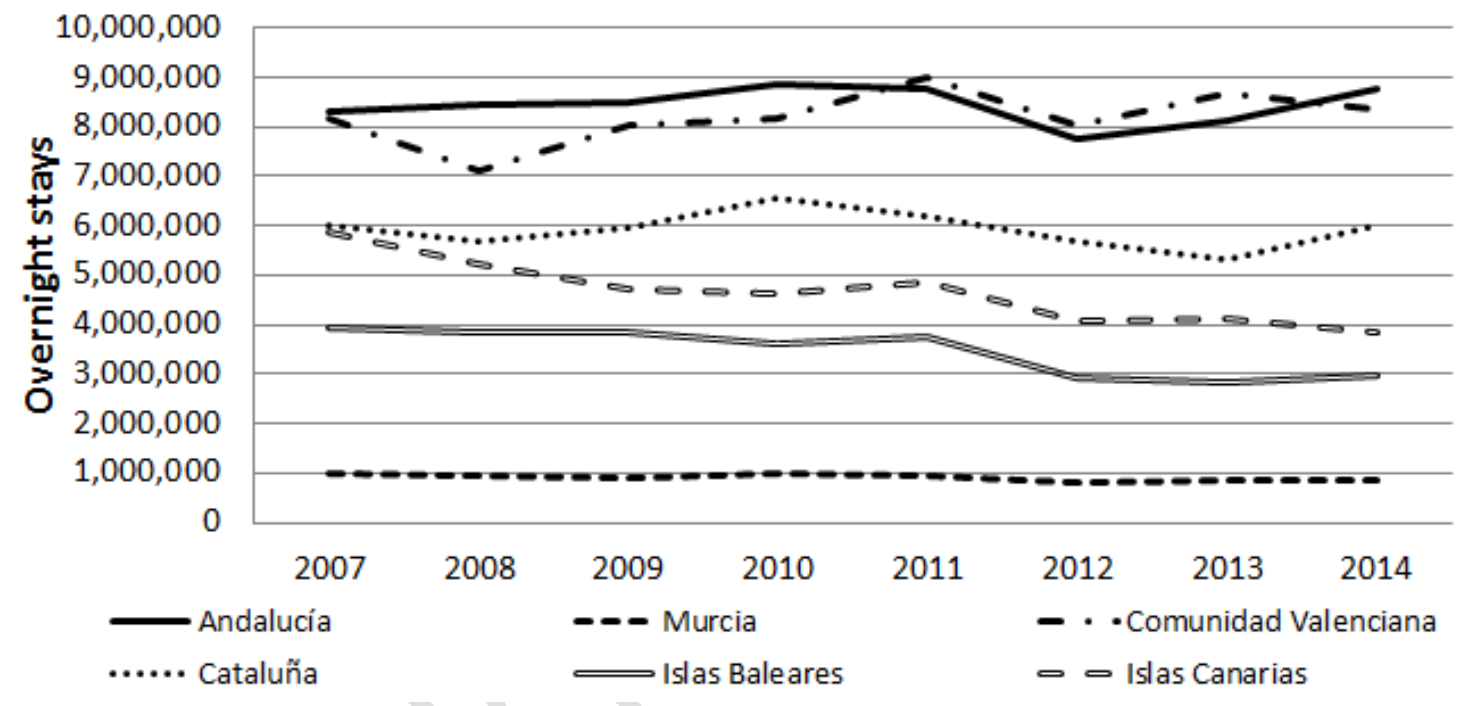

Figure 1 Overnight stays generated by the IMSERSO trips

The employment generated through tourism activity in the low season affects in the income of destination regional administrations, which recover the amount invested by IMSERSO in full. Specifically, for every euro that IMSERSO invests, the Spanish government recovers 1.54 euros through social security contributions, savings in unemployment benefits and revenue from Personal Income Tax "Impuesto sobre la Renta de las Personas Físicas" (IRPF), Tax Value Added "Impuesto sobre el Valor Añadido (IVA), and other taxes (PwC, 2012). This, together with the impact on employment makes this programme a highly efficient alternative for economic sustainability.

In the 2014-2015 season, the IMSERSO offered 896,666 trips, of which 817.488 took place in coastal destinations ( $91.17 \%$ of the total trips). However, for these destinations, the IMSERSO received 1,648,983 applications, so just half of them were accepted (49.58\%) (IMSERSO, 2015a). This is because since the beginning of the IMSERSO programme, the demand for trips has been higher than the supply. Therefore, there is the application of selection criteria, which weigh the variables of age, economic situation, previous participation in the programme and belonging to a large family (IMSERSO, 2016). With regard to the volume of employment 
generated, it is calculated that 11,202 direct jobs in total were supported of which 9,744 were in coastal destinations (2013/14, the latest for which statistics are available). In terms of the distribution of jobs per region, these were: Valencia (24\%), Andalucía (20\%), Islas Canarias (19\%), Islas Baleares (11\%), Cataluña (11\%) and Murcia (2\%) (IMSERSO, 2014). The remaining $13 \%$ are accounted by those generated in inland areas. Furthermore, by adding the jobs generated in other activities in the tourism sector (jobs in road transport or air, travel agencies, health care, insurance, etc.) to the direct ones created, the IMSERSO trips generated 77,294 new jobs, of which 67,246 were created in the coastal destinations analysed (IMSERSO, 2014).

Regarding the number of overnight stays made by tourists in the IMSERSO programme, $7,353,167$ were recorded in the 2013/2014 season of which $6,896,488$ took place in the regions analysed in this study (IMSERSO, 2014). With the information above, the number of overnight stays necessary to create a direct/indirect job has been calculated (Table 1).

Table 1 Overnight stays and jobs created by the IMSERSO trips (2013/2014 season)

\begin{tabular}{|c|c|c|c|c|c|}
\hline & $\begin{array}{l}\text { Overnight stays } \\
\text { by region }\end{array}$ & $\begin{array}{l}\text { Direct jobs } \\
\text { created }^{*}\end{array}$ & $\begin{array}{l}\text { Overnight stays / } \\
\text { Direct jobs } \\
\text { created }\end{array}$ & $\begin{array}{l}\text { Indirect jobs } \\
\text { created } *\end{array}$ & $\begin{array}{l}\text { Overnight stays / } \\
\text { Indirect jobs } \\
\text { created }\end{array}$ \\
\hline Andalucía & $1,665,721$ & 2,240 & 743.63 & 15,459 & 107.75 \\
\hline Murcia & 192,837 & 224 & 860.88 & 1,546 & 124.73 \\
\hline Comunidad Valenciana & $1,920,437$ & 2,688 & 714.45 & 18,551 & 103.52 \\
\hline Cataluña & 865,719 & 1,232 & 702.69 & 8,502 & 101.83 \\
\hline Islas Baleares & $1,261,173$ & 1232 & $1,023.68$ & 8,502 & 148.34 \\
\hline Islas Canarias & 990,601 & 2,128 & 465.51 & 14,686 & 67.45 \\
\hline All regions & $6,896,488$ & 9,744 & 707.77 & 67,246 & 102.56 \\
\hline
\end{tabular}

There are few limits to the potential for growth in the IMSERSO programme over the medium term. On the supply side, the Spanish tourism sector has sufficient infrastructure and human resources to accommodate a greater volume of travellers in the low season, including transportation and other services. On the demand side, the growth of the elderly population together with improved health into older age mean that there is a growing demand for tourist services amongst this segment. It is estimated that the population over age 64 will double in 40 years and will represent more than $30 \%$ of the total (INE, 2010). Recent studies, as the one by Garcés Ferrer, Ferri Sanz, Durá Ferrandis, McCabe, and Sánchez García (2015), have pointed to the links between active aging, tourism participation and health within a Spanish context, suggesting that the benefits of these types of programmes may potentially extend into decreased costs of health and social care support, in addition to increased employment and vitality of tourism destination regions. However, it is important to understand the nature of these economic effects and the potential offered by social tourism for strategies against seasonality, a task to which we now turn.

\section{Data sources and methodology}




\subsection{Data sources}

Spain, which is located in southern Europe, is organized territorially into 17 regions. IMSERSO trips take place in different coastal destinations ${ }^{1}$ located in six of these regions analysed in this study: Andalucía, Murcia, Valencia, Cataluña, Islas Baleares and Islas Canarias (Figure 2). In addition, it is noted that there are other coastal destinations whose overnight stays in hotels are recorded by the INE. However, these are not accounted for in this study because they are not consolidated destinations by the IMSERSO ${ }^{2}$.

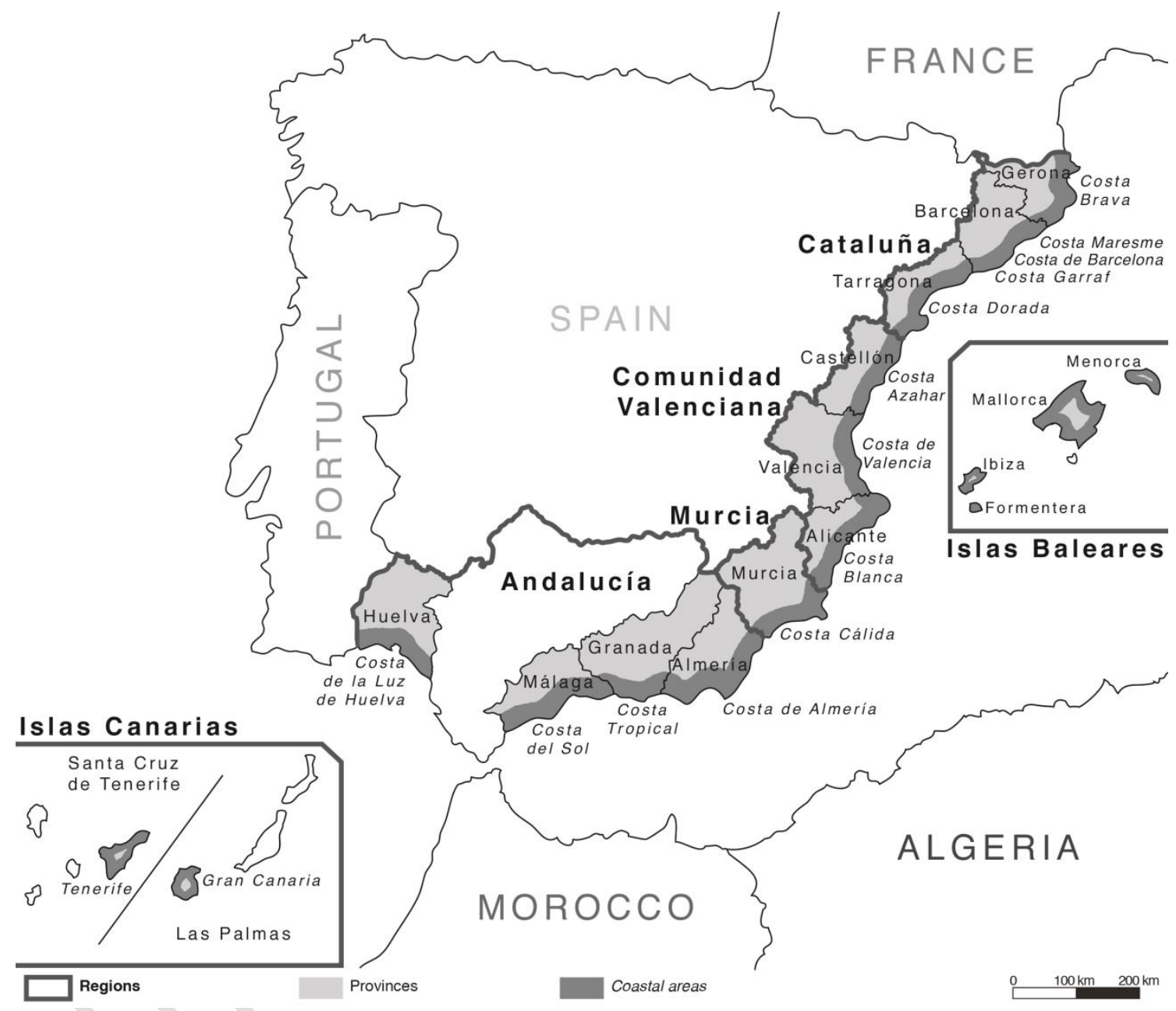

Figure 2 Map of Spain showing the destination where the IMSERSO trips take place

The estimation of the deseasonalising impact of social tourism through IMSERSO trips has been performed using the overnight stays in 3- and 4-star hotels located in the destinations. The data for this analysis come from different primary sources on a monthly basis encompassing the period 2007 to 2014: (a) Number of overnight stays by domestic and international travellers (INE, 2014b), and (b) employment generated (INE, 2014c), both series in hotels located in the coastal destinations analysed; (c) Number of overnight stays by domestic and international travellers (INE, 2014b), and (d) employment generated (INE, 2014c), both series in hotels of all categories in the provinces where the coastal destinations are located; (e) Number of overnight stays by domestic travellers who are beneficiaries of IMSERSO trips-this series have been developed specifically for this work thanks to collaboration between the researchers 
and IMSERSO-(IMSERSO, 2015b), and (f) employment generated or maintained by the IMSERSO (IMSERSO, 2014) ${ }^{1}$, both series in 3- and 4-star hotels in the regions studied analysed.

Due to the different territorial scales of the primary sources available and with the aim of homogenizing the data to achieve greater precision in the results, some adjustments were needed. The numbers of domestic and international overnights, as well as the employment generated in 3- and 4-star hotels in the destinations were projected using the percentages of these segments in their respective provincial series. So finally, the variables used in this study are: (i) Number of overnight stays in 3- and 4-star hotels in regions where the coastal destinations are located (domestic, international and overall); (ii) Number of overnight stays in 3- and 4-star hotels generated by IMSERSO trips; (iii) Number of overnight stays in 3- and 4star hotels (domestic and overall) without counting the overnight stays by beneficiaries of IMSERSO trips; (iv) employment (overall and generated by the IMSERSO trips) in 3- and 4star hotels in each region.

\subsection{Methodology}

To conduct our analysis of the counter-seasonal effects of social tourism programmes, we employed an adapted Gini index decomposition by sources developed by Lerman and Yitzhaki (1985). This method was originally used in the field of economic inequality, and more recently in tourism (Cisneros-Martínez \& Fernández-Morales, 2015; Duro, 2016; Fernández-Morales et al., 2016; Fernández-Morales \& Mayorga-Toledano, 2008; Halpern, 2011). The Gini index (without a marginal decomposition) is a measure of concentration that has been widely used as an indicator of the annual concentration degree of tourism demand, including among others, the recent works of Cisneros-Martínez and Fernández-Morales (2016), Coshall et al. (2015), Fernández-Morales and Cisneros-Martínez (2015), Fernández-Morales and Martín-Carrasco (2015), and Martín Martín et al. (2014). For a variable X which quantifies the demand for one year (monthly data in this study), the Gini index is obtained as

$$
G=\frac{2 \operatorname{Cov}(X, F(x))}{\mu}
$$

Where $\mu$ and $F(X)$ represent the mean and the distribution function of $\mathrm{X}$ respectively. The Gini index ranges from 0 to 1 ; as $\mathrm{G}$ approaches to 1 , it indicates a higher degree of seasonal concentration of demand in a few months, while values close to 0 determine a more equitable distribution in time, i.e. lower seasonality. The extreme value 0 is only achieved if demand is constant in every month of the year analysed.

The Gini index is a measurement approach of the seasonal concentration of demand which allows a decomposition by sources, when the demand $\mathrm{X}$ is composed of the sum of several

\footnotetext{
${ }^{1}$ Direct and indirect employment generated or maintained by the IMSERSO in the low season are estimated in the yearly IMSERSO reports by the Special Commissions on Employment Monitoring "Comisiones Especiales de Seguimiento del Empleo", which are composed of representatives of the central and autonomous administration, business organizations, and trade union centres in each region (IMSERSO 2014).
} 
segments, $X_{i}, i=1,2, \ldots, K$, in such a way that $X=\sum_{i=1}^{K} X_{i}$. According to Lerman and Yitzhaki (1985) the Gini index of the overall demand can be decomposed as

$$
G=\sum_{i=1}^{K} \frac{\mu_{i}}{\mu} G_{i} R_{i}=\sum_{i=1}^{K} \frac{\mu_{i}}{\mu} C_{i}
$$

where $G_{i}$ represents the Gini index of the segment $i$, and $R_{i}$ is the Gini correlation between the demand of the segment $i$ and the overall demand. $R_{i}$ is a measure of correlation that takes into account both values and ranks (Yitzhaki \& Schechtman, 2013: 40). The quotient between $\mu_{i}$ and $\mu$, is usually called $S_{i}$, which represents the share of the segment $i$ on the overall demand. The product of $G_{i}$ and $R_{i}$, is often called the concentration ratio, $C_{i}$.

This result shows that the repercussion that the distribution of each segment $i$ has on the concentration of the overall demand depends on its level of concentration (measured by $G_{i}$ ), the weight that demand of $i$ has in the overall demand $\left(S_{i}\right)$, and the level of correlation with the distribution of the overall demand $\left(R_{i}\right)$. This last component can be negative, so that a segment whose demand is highly concentrated in seasons of low overall demand, i.e. with negative $R_{i}$, will have a negative effect on the overall Gini index.

The additive decomposition of the Gini index developed by Lerman and Yitzhaki (1985) permits the calculation of Relative Marginal Effect (RME) on the Gini index of the overall demand that would produce a relative increment of the demand for a segment, maintaining its temporal distribution. This effect allows us to quantify the impact of social tourism in terms of its reduction of seasonality in the destinations under scrutiny. The RME of the segment $i$ $\left(R M E_{i}\right)$, also called the elasticity of the Gini Coefficient with respect to the mean from component $i\left(\eta_{i}\right)$ (Podder, 1993; Podder \& Chatterjee, 2002), is obtained as

$$
\eta_{i}=\frac{1}{G}\left(\frac{\mu_{i}}{\mu}\left(G_{i} R_{i}-G\right)\right)
$$

Thus in this study, the $R M E_{i}$ represents the percentage of change in the overall Gini index, when the number of travellers in the IMSERSO programme is increased by $1 \%$, keeping constant the monthly distribution of social tourists as well as the number and monthly distribution other travellers remains constant. The sum of the RME must be equal to 0 , i.e. $\sum_{i=1}^{K} \eta_{i}=0$ (Lerman \& Yitzhaki, 1985).

In addition, to study the evolution that the seasonal concentration indicator has experienced over the period analysed, the decomposition proposed by Podder and Chatterjee (2002) has been used. The change experienced by the Gini index between the periods $s$ and $t, \Delta G=G(t)$ $G(s)$, can be approximated by the expression

$$
\Delta G \approx \sum_{i=1}^{K} C_{i} \Delta S_{i}+\sum_{i=1}^{K} S_{i} \Delta C_{i}
$$


where $\Delta S_{i}=S_{i}(t)-S_{i}(s)$, and $\Delta C_{i}=C_{i}(t)-C_{i}(s)$. The first sum in (4) is called Share Effect (SE) representing the change in the overall Gini index that is due to the changes in the share of segments between $s$ and $t$. The second sum in (4) is called Concentration Effect (CE) and stands for the change in the overall Gini index that is due to the changes in the level of concentration in the segments between $s$ and $t$. The weights in both sums of (4), $C_{i}$ and $S_{i}$ are calculated in this paper following the recommendation of Podder and Chatterjee (2002), by means of $C_{i}=$ $\left(C_{i}(t)+C_{i}(s)\right) / 2$ and $S_{i}=\left(S_{i}(t)+S_{i}(s)\right) / 2$.

The proposed methodology allows for the evaluation of the level of seasonal concentration of all tourism demand (both overall demand and domestic and international segments) in the destinations analysed. But the greatest interest in this study is to quantify the deseasonalising effect of the demand generated by the IMSERSO trips. Thus, we can assess both the effect of this social tourism programme each year and across the whole the period. Finally, by analysing the evolution of $R M E_{i}$, especially in the data for the last year, it is possible to predict how an increase of the IMSERSO trips contributes towards reducing the overall Gini index.

Furthermore, the estimation of seasonal factors has been used through the multiplicative decomposition of the time series to describe the seasonal patterns observed in the different regions and segments. Additionally, a multivariate graphic, biplot, has been used to present the $R M E_{i}$ of the last year analysed. This technique was used for the first time jointly with the decomposition of the Gini index in the work of Fernández-Morales et al. (2016).

\section{Counter seasonal effects of IMSERSO trips}

\subsection{Recent evolution of the demand in the 3-and 4-star segment}

As mentioned previously, this study focused on demand in the 3- and 4-star hotel segment, since this is the segment where most overnight stays by IMSERSO tourists take place. This segment has a very high importance in the destinations studied; with percentages of the total overnight stays ranging from $85 \%$ in Cataluña to $90 \%$ in Islas Baleares. In regions such as Andalucía, Cataluña, Islas Baleares and the Islas Canarias, the total annual volume of overnight stays in the coastal destinations included in this study exceeded 20 million, reaching more than 40 million in all the destinations studied in the Islas Baleares.

Distinguishing by origin of tourism demand, international demand has presented mainly a growing trend across the regions as shown in the left column of Figure 3. Domestic demand has suffered more from the effects of the economic crisis, showing ups and downs in the regions of Andalucía, Comunidad Valencia and Cataluña; and a clear downward trend in the period analysed in the Islas Baleares, Islas Canarias and Murcia. The important international demand of the two island regions, Islas Canarias and Islas Baleares, has compensated the fall in domestic demand; so that the total demand in 2011 was already at a higher level than 2007, and it has held until the end of the period analysed.

\subsection{Effects on the seasonal pattern}


Generally, across the regions, the seasonal pattern of the monthly distribution of overnight stays, both for domestic and international demand presents a rather accentuated unimodal profile, with the peak season in the summer months, noting especially August, as seen in the profiles of seasonal factors shown in the graphs on the right column of Figure 3. With respect to domestic demand, in regions such as Andalucía and Islas Baleares, the seasonal factor in August reaches a very high value (3). The other regions also show a high value in August, whereas Islas Canarias and Valencia have the smallest values (around 2). Moreover, the seasonal concentration of international demand is less than the domestic in four of the regions, although Cataluña and Islas Baleares are much higher, with seasonal indices for July and August exceeding 4.

To investigate the deseasonalising effect of the IMSERSO trips, the seasonal factors of total domestic demand and domestic demand excluding IMSERSO trips (Domestic ${ }^{\mathrm{WIT}}$ ) have been compared. In the graphs on the right column of Figure 3 we observe that in the six regions, the IMSERSO demand significantly softens the extent of seasonal factors.

The effect of the additional demand during the winter months thanks to the IMSERSO trips favours a decrease in the amplitude of the seasonal pattern between the months of summer season; and the winter season in the overall domestic demand. That is, the profile of seasonal patterns is noticeably softened, since the weight that the summer months have in the overall domestic demand is reduced in accounting for a greater volume of overnight stays in low season months.

This effect can be seen clearly in the graphs of seasonal factors (F) in Figure 3. In all regions the seasonal pattern of domestic demand excluding the IMSERSO trips (Domestic) is more pronounced than the one for the overall domestic demand. This can be appreciated with some seasonal factors in the higher months of the peak season within the distribution of overnight stays that do not include demand IMSERSO (Domestic ${ }^{\text {WIT }}$ ), while in the winter months show lower seasonal factors. Therefore, in the absence of winter demand generated by IMSERSO trips, seasonal patterns of domestic demand would be more pronounced than those observed currently. 

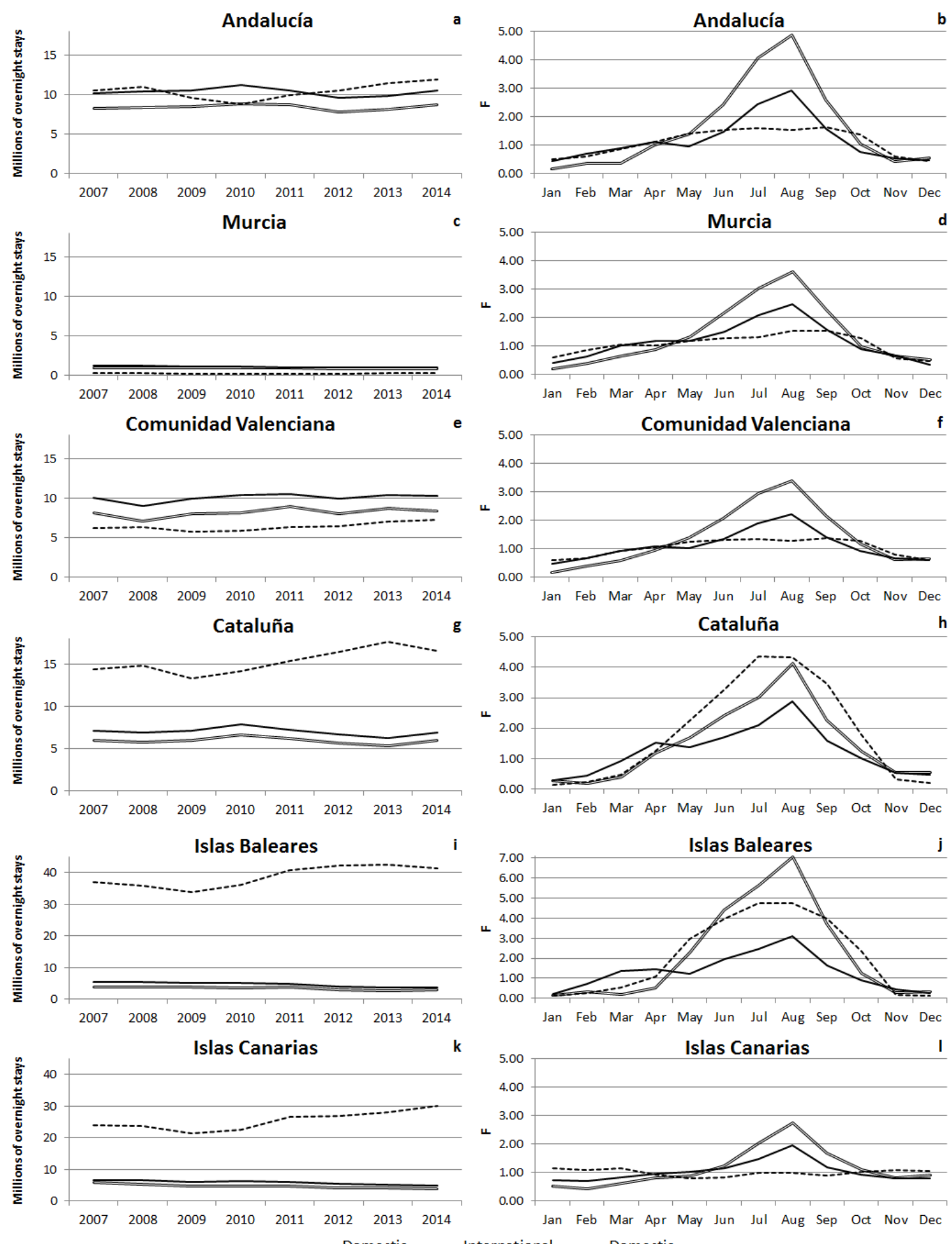

Jan Feb Mar Apr May Jun Jul Aug Sep Oct Nov Dec

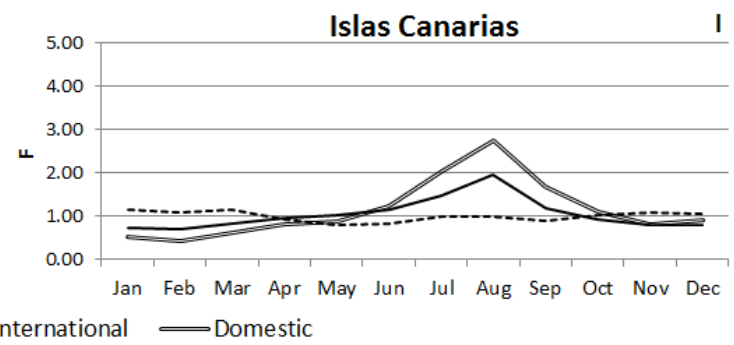

Figure 3 Domestic, Domestic ${ }^{\text {WIT }}$ and International demand: Absolute values and seasonal factors

Although this effect is important in all the regions, in Andalucía, Murcia, Comunidad Valenciana and Islas Canarias, the domestic demand has a more pronounced seasonal pattern, as international demand in these four regions presents a much more moderate seasonal profile than domestic demand. So in these regions, the strategy of the IMSERSO is addressed to the segment that shows a higher annual temporary decomposition. However, in Cataluña and Islas Baleares, the seasonal pattern of international demand is more pronounced than domestic, so 
despite the dampening effect on seasonality generated by domestic winter demand provided by IMSERSO tourists, it may have a more limited impact in the total figures.

\subsection{Seasonal Concentration}

To quantify the degree of annual seasonal concentration of monthly seasonal patterns in coastal destinations of the regions receiving IMSERSO tourists, the Gini index estimation was used. In Figure $4 \mathrm{a}$, the estimated evolution of the Gini index calculated across the distribution of overnight stays in 3- and 4-stars hotels in all tourist destinations is presented. It can be seen that there are notable differences in the degree of seasonal concentration between regions. Those regions facing the most serious problem are Cataluña and Islas Baleares with indices above 0.4 throughout the period. Andalucía, Comunidad Valenciana and Murcia also have notable indices with values between 0.3 and 0.4. Only Islas Canarias shows reduced indices, with values less than 0.06. But the most relevant aspect of this analysis is that, except in Islas Canarias, the degree of seasonal concentration shows an increasing trend in all regions. This does not mean, a priori, that the IMSERSO programme does not have a significant deseasonalising effect, but further action is needed for this trend to be reversed.

There are major differences between the regions regarding the degree of seasonal concentration since the levels of domestic and international demand varies according to the destination. In Figure $4 \mathrm{~b}$ the degree of seasonal concentration of the international segment is shown, estimated by the Gini index. In the two regions with the highest degree of seasonal concentration; Cataluña and Islas Baleares, the international segment has an even bigger effect on seasonality, reaching the higher index values, and also, a rising trend observed over the period; in addition, this segment has a very high share in both regions, $71 \%$ and $92 \%$ respectively in 2014. Instead, in the Andalucía, Murcia and Comunidad Valenciana regions, the international segment, despite presenting an increasing trend, shows lower indices values than the overall demand, so the international segment could show a slight deseasonalising effect.

The IMSERSO trips are included in the domestic segment. However, the overnight stays corresponding to the IMSERSO trips were discounted with the intention of obtaining the Domestic $^{\text {WIT }}$ segment (Figure 4c). This segment shows a very high degree of concentration. In all regions, except Cataluña, the Gini indices of Domestic ${ }^{\text {WIT }}$ tourists are even higher than those of the international segment. However, what is relevant here is the finding of a significant reduction that is achieved in all regions when the IMSERSO trips are incorporated into the domestic segment (Figure 4d). The indices of seasonal concentration in Figure $4 \mathrm{~d}$ are much lower than those in Figure 4c, which shows the important effect of this type of social tourism on the seasonal concentration of domestic tourism in 3-and 4-stars hotels located in the regions of study. 

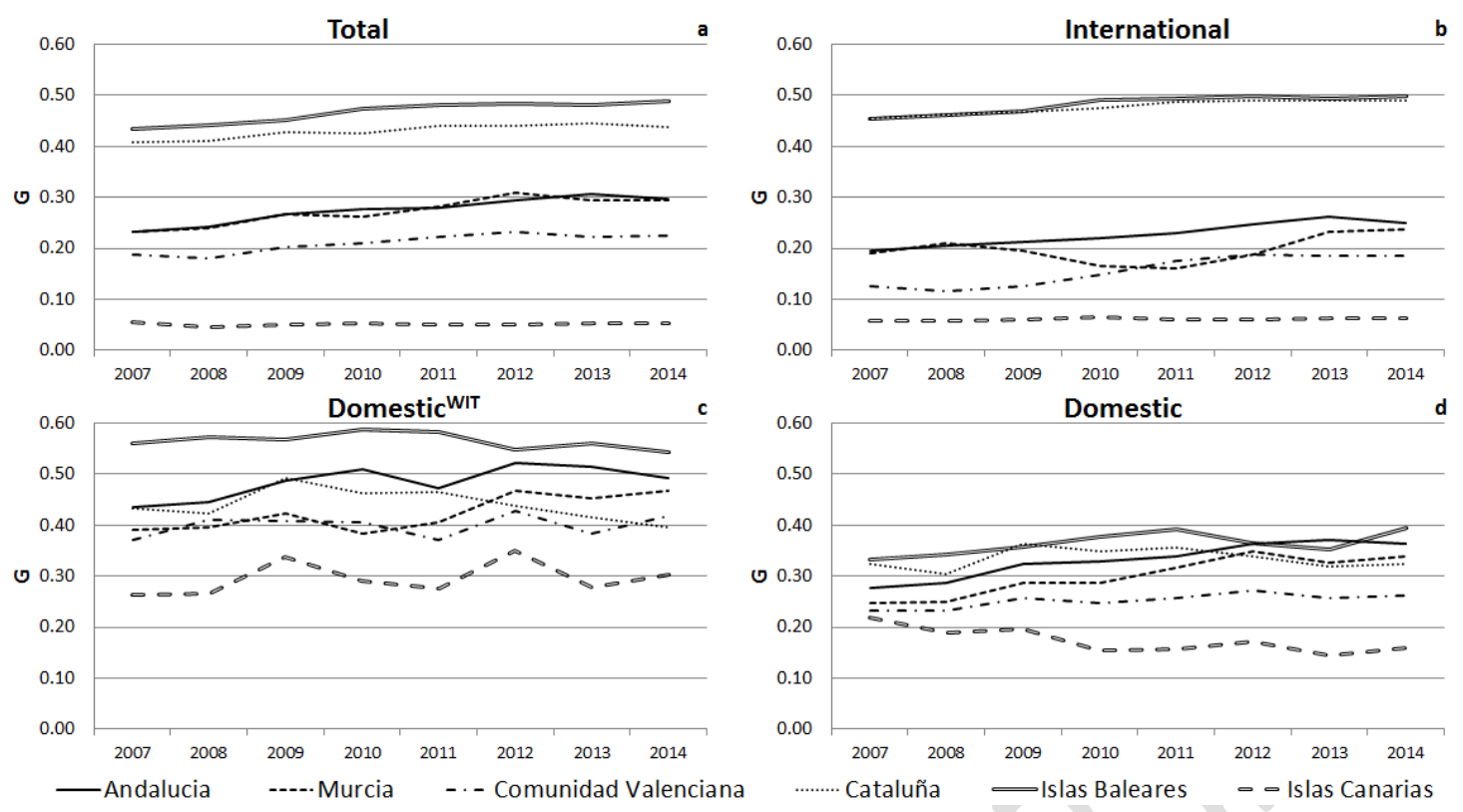

Figure 4 Seasonal concentration of 3- and 4-stars hotels demand (Gini index)

To deepen the effects of seasonality, measured by the Gini index, the change experienced by the Gini index by incorporating the IMSERSO trips is presented in Figure 5 in both the number of overnight stays of domestic tourists (Figure 5a) and the total number of overnight stays (Figure 5b). The change experienced in the Gini index can be appreciated visually as the horizontal separation from the diagonal so that the variable on the horizontal axis does not include the IMSERSO trips (Domestic ${ }^{\text {WIT }}$ and Total ${ }^{\text {WIT }}$ respectively) and the variable on the vertical axis includes them (Domestic and Total respectively).

If we focus only on the domestic segment, Figure 5a, we find that the effect is noticeable in all regions although slightly lower in Cataluña; both those with a high index of seasonal concentration, in the top of the graphic, as in other regions such as Islas Canarias with a lower Gini index.
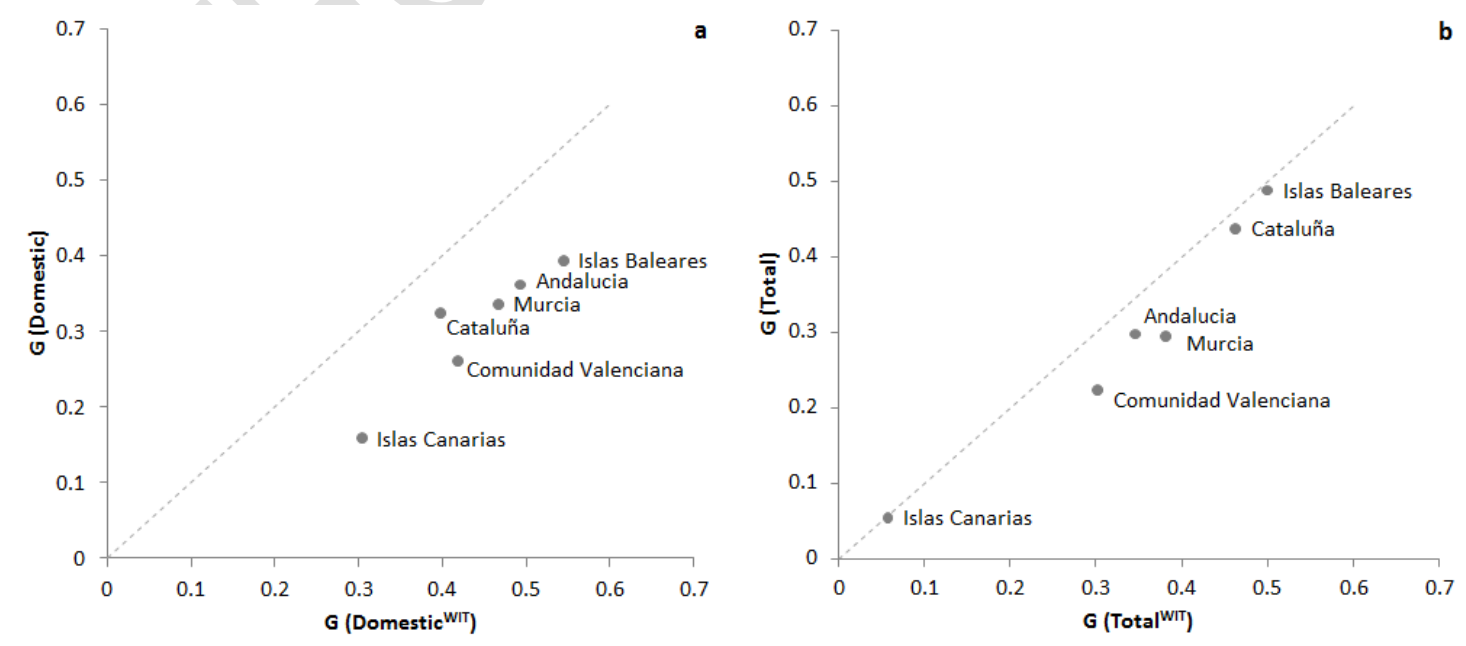

Figure 5 Change in the Gini index by incorporating the IMSERSO trips (2014) 
However, if the analysis is performed together with the overall volume of overnight stays, the results show some significant differences (Figure 5b). The regions where the greatest change in the Gini index of the total annual overnight stays occurs are Andalucía, Comunidad Valenciana y Murcia. Instead, both Islas Baleares y Cataluña in the area of regions with high level of seasonal concentration, and Islas Canarias in the area of low level, the effect is very small. This effect is because the share of domestic tourism in these three regions is much lower than the international tourism, surpassing the international segment $70 \%$ in the three regions.

\subsection{Decomposition of the temporary change in $G$}

Seasonal concentration of overall tourism demand in the 3- and 4-star hotel sector has increased in all regions studied, with the exception of Islas Canarias, as already mentioned above. For a deeper insight into how this phenomenon has occurred and what role the IMSERSO trips have played, the decomposition proposed by Podder and Chatterjee (2002) has been applied. The results are shown schematically in Figure 6. First, it can be seen that the highest increases in the Gini index between 2007 and 2014 have been observed in Murcia, Andalucía and Islas Baleares, with increases higher than 0.05. In addition, Cataluña and Comunidad Valenciana have also presented significant increases, around 0.03 .

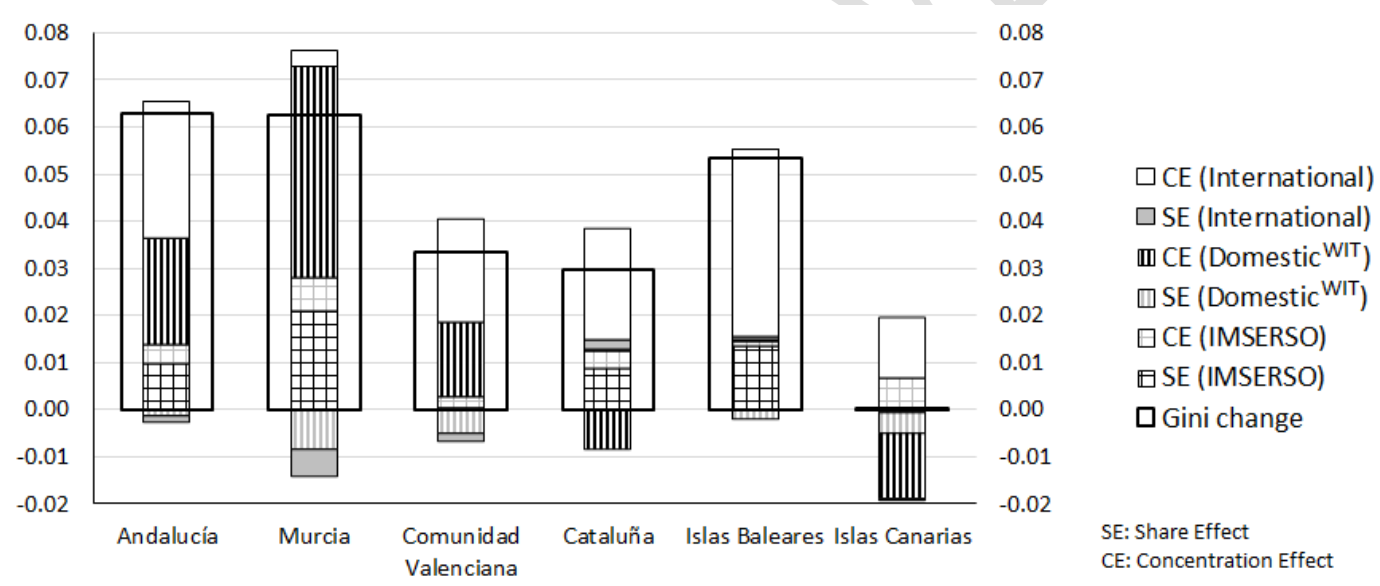

Figure 6 Decomposition of the change in G (2007-2014)

Regarding the role of the evolution experienced by IMSERSO trips, it can be seen that in all regions where seasonal concentration has increased significantly, these trips have had positive effects on that increase. In particular, the SE has been considerable in most of these regions with values equal or higher than 0.09 in Andalucía, Islas Baleares, Cataluña and Murcia. The decrease that occurred between 2007 and 2014 in the volume of overnight stays generated by the IMSERSO trips in the total demand for these destinations has caused an increase in the general level of seasonal concentration which has led to a relative decline of the deseasonalising effect of this segment. Instead, the CE of the IMSERSO trips is smaller than the SE in these regions because the change in the concentration index of this segment has a least important magnitude.

Besides the effect caused by the decreasing number of IMSERSO trips in increasing seasonal concentration in the five regions, there are other components that have contributed even more 
importantly. In these regions, the indices of annual seasonal concentration of international demand have increased significantly ranging from 0.03 in Cataluña to 0.05 in Andalucía. This means that remarkable $\mathrm{CE}$ of the international segment in these regions is observed, especially in Islas Baleares (0.04) and Andalucía (0.03). Only in Murcia, is the CE of the international segment not very high due to the very small weight of this segment in the region. By contrast, the SE of the international segment is not very high in these regions, with values that never exceed +-0.006 .

Unlike the international segment, Domestic ${ }^{\text {WIT }}$ tourists have only increased the seasonal concentration in the Andalucía, Comunidad Valenciana and Murcia regions; contrary to what happened in Islas Baleares and Cataluña in which there has been a decrease. Therefore, CE of considerable magnitude in the Domestic ${ }^{\text {WIT }}$ segment is observed only in Andalucía, Comunidad Valenciana and Murcia with values higher than 0.015. As for the SE of this segment, they are low or negative, due to the fall in domestic demand in the period observed.

The Islas Canarias have shown a different behaviour pattern in terms of the evolution of the general seasonal concentration, which has remained practically constant. However, this behaviour is the result of offsetting effects. There has been a slight increase in seasonal concentration of international demand, which given its great importance in this destination has generated a significant positive CE; and furthermore, there has been an increase in seasonal concentration of the IMSERSO trips, reflected in the positive CE of this segment. However, these effects are practically offset by the negative effects of the Domestic ${ }^{\text {WIT }}$ segment, both the $\mathrm{SE}$ and CE.

\subsection{Relative marginal effects}

Comparing the seasonal patterns and levels of observed seasonal concentration which have been obtained, excluding the demand generated by the IMSERSO trips, have allowed us to evaluate the impact this social tourism programme has had on the seasonality in destinations where such trips occur. Nevertheless, it is possible to go a step further by calculating using the $R M E_{i}$ on the indicator of seasonal concentration, the impact of an increase in the share of the total demand of each segment analysed. Therefore, the $R M E_{i}$ helps us to identify those segments that can contribute to the seasonal adjustment of total demand by growing their share.

To facilitate the analysis of $R M E_{i}$, Figure 7 shows the estimated values for the IMSERSO (Figure 7a), Domestic ${ }^{\text {WIT }}$ (Figure 7b) and International (Figure 7c) segments, for each year observed. Firstly, the $R M E_{i}$ indicates that in all regions, the IMSERSO trips generate negative $R M E_{i}$. This indicates that increasing the volume of the demand generated by IMSERSO trips would produce a deseasonalising effect in all the regions. This indicates that there is scope to further enhance social tourism and that doing so would reduce the seasonal concentration in demand.

However, the magnitude of the $R M E_{i}$ that the IMSERSO trips generate is not uniform. The regions with negative $R M E_{i}$ of greater magnitude in the social tourist segment are Andalucía, Murcia, and especially, Comunidad Valenciana. Although the negative $R M E_{i}$ of these three regions have been reduced slightly, still they show a significant potential deseasonalising effect. However, in Cataluña and Islas Baleares, the magnitude of the potential deseasonalising effect 
is lower, with negative $R M E_{i}$ closer to 0 throughout the period. The case of Islas Canarias is more erratic, being in an intermediate point between the two groups of regions.

Consistent with previous results, the Domestic ${ }^{\text {WIT }}$ segment has positive $R M E_{i}$ in all regions, except in the last three years analysed in Cataluña. This indicates that the domestic segment is generally very seasonal and that its growth would lead to increased seasonal concentration. Again, this can be differentiated for the regions where the $R M E_{i}$ is more significant, Andalucía, Murcia and Comunidad Valenciana; and the regions where the effect is smaller in magnitude, Cataluña and Islas Baleares. This difference is partly explained by the role of international demand that as seen in Figure 7, has positive $R M E_{i}$ in Cataluña and Islas Baleares, whereas Andalucía, Murcia and Comunidad Valenciana show negative $R M E_{i}$.
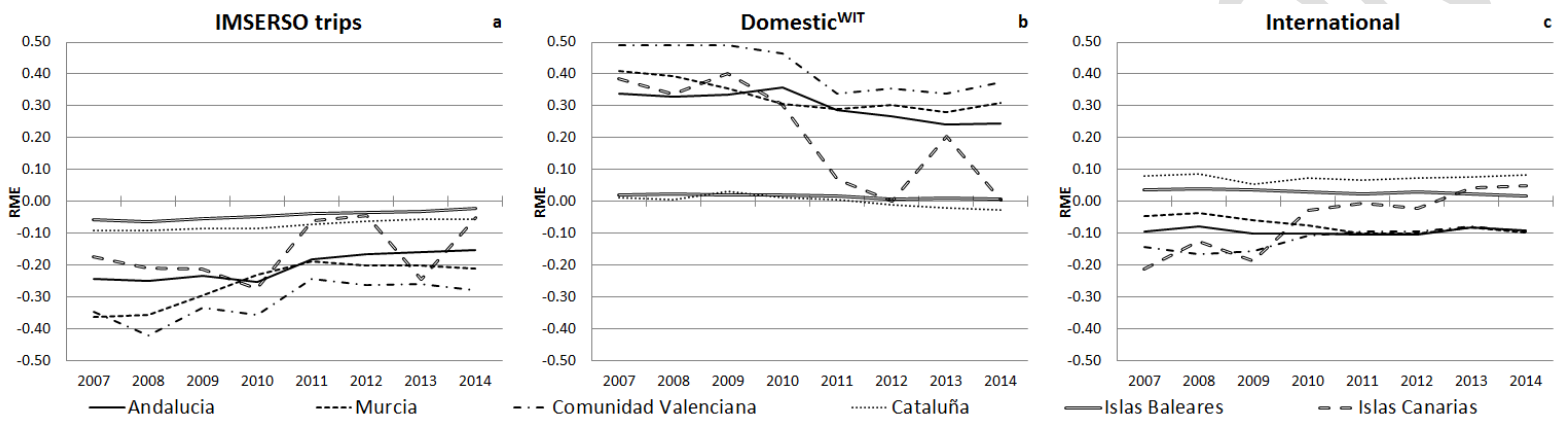

Figure 7 Relative Marginal Effects

From the analysis of the estimated $R M E_{i}$, we can assume that there is room, at least in the short term, to further enhance the social tourism segment through the IMSERSO activity. This effect has a variable magnitude between regions, being Comunidad Valenciana, Murcia and Andalucía, the regions where the deseasonalising effect is of greater magnitude.

In order to better understand the differences of the $R M E_{i}$ between regions in the three segments analysed, particularly in the demand generated by the IMSERSO trips, a biplot is presented in Figure 8 corresponding to the estimations for the last year available, 2014. In this multivariate graphic, for the six regions included in this study, the components of the decomposition of the Gini index are represented: $G i, S_{i}$ and $R_{i}$ together with the $R M E_{i}$. These four variables are represented by arrows pointing in the direction of the highest values of each. The segments in each region are situated in the location which approximates their values regarding the four variables considered. Therefore, the segments that have the most significant negative $R M E_{i}$ are located in the area of the left lower quadrant, since the $R M E_{i}$ variable points to the upper right quadrant. 


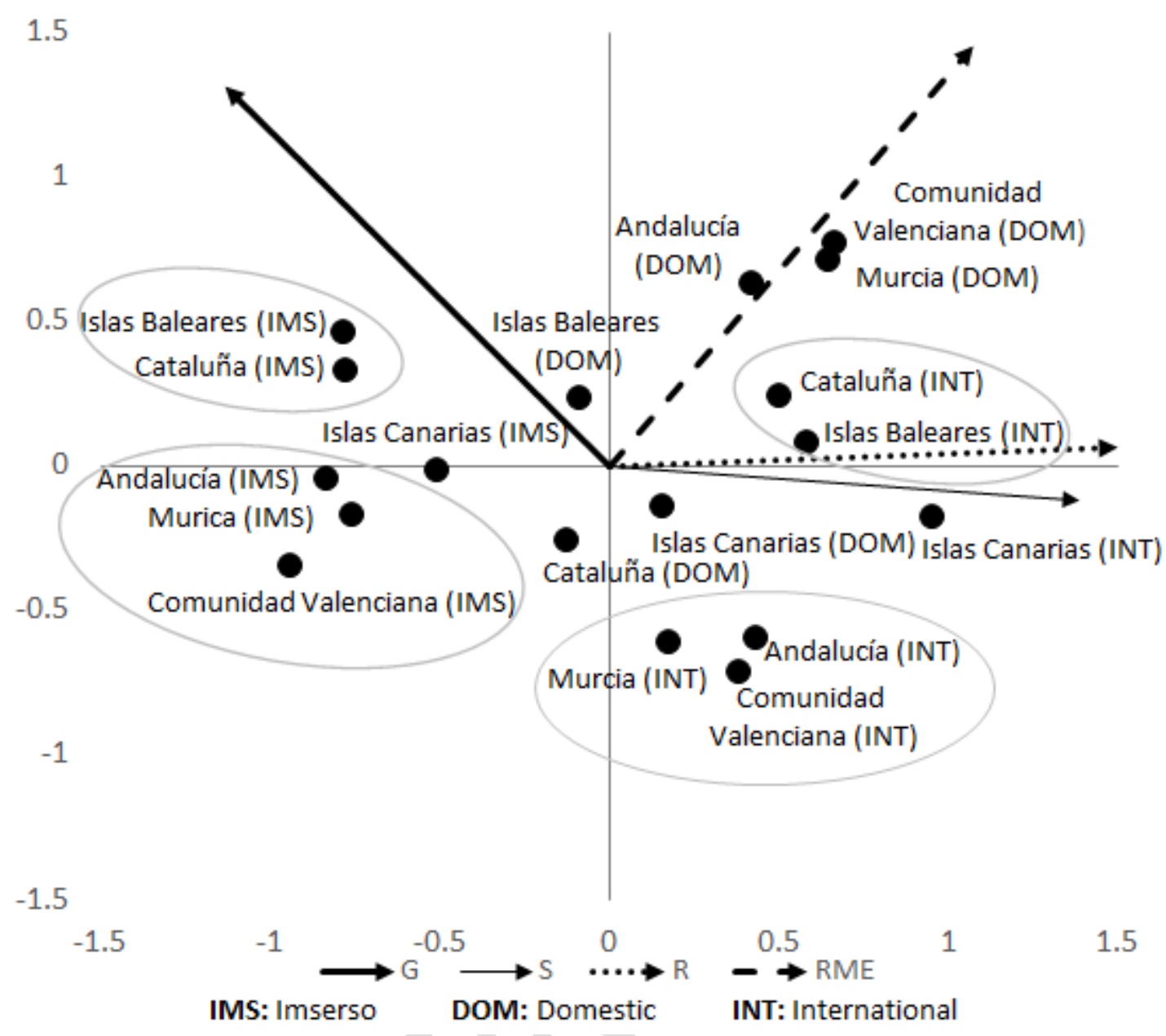

Figure 8 Biplot of the Gini decomposition, 2014

With regard to IMSERSO segment, the Murcia, Andalucía and Comunidad Valenciana regions can be grouped together, and the Islas Baleares and Cataluña into a second grouping. The Islas Canarias is in an intermediate position. The first group has the greater magnitude negative $R M E_{i}$, and therefore, these are the regions with the greatest potential to increase social tourism as a means to reduce the seasonal concentration. In addition, this group is characterized by a highest $S_{i}$ and a greater $R_{i}$ in comparison with the second group, as well as by a lower Gini index. The second group also has a negative $R M E_{i}$, but of lesser magnitude and also lower $S_{i}$ in relation to the IMSERSO segment and less $R_{i}$ as a share of the total.

With respect to the international segment, another difference between the two groups of regions is displayed on the biplot. The important $S_{i}$ of this segment in Cataluña and Islas Baleares, along with its seasonal distribution, causes them to be placed in an area of the right upper quadrant, indicating a positive $R M E_{i}$. The opposite happens in the regions of Andalucía, Murcia and Comunidad Valenciana, located in the lower left quadrant, indicating negative $R M E_{i}$, but smaller than the IMSERSO segment in these same regions.

\subsection{Effects on employment seasonality}

Employment in the hotel sector represents a serious problem caused by seasonality. Therefore, it is important to try to measure how many jobs are created and maintained by the IMSERSO 
trips in the hospitality sector in the low season. The seasonal concentration of employment in 3- and 4-stars hotels in the coastal destinations where IMSERSO trips take place presents important differences. Such seasonal concentration has been quantified by the Gini index, and the evolution over the period studies is shown in Figure 9. First, it can be highlighted that the regions with the most acute problem of seasonality in employment in this hotel segment are Islas Baleares and Cataluña. In second position in terms of the severity of the problem of seasonal employment are Andalucía, Murcia and Comunidad Valenciana. Islas Canarias, however, shows a very low level of seasonal concentration. These results are consistent with the measurement of seasonal concentration of demand outlined previously. Seasonal patterns of employment in the regions are very similar to the hotel demand patterns.

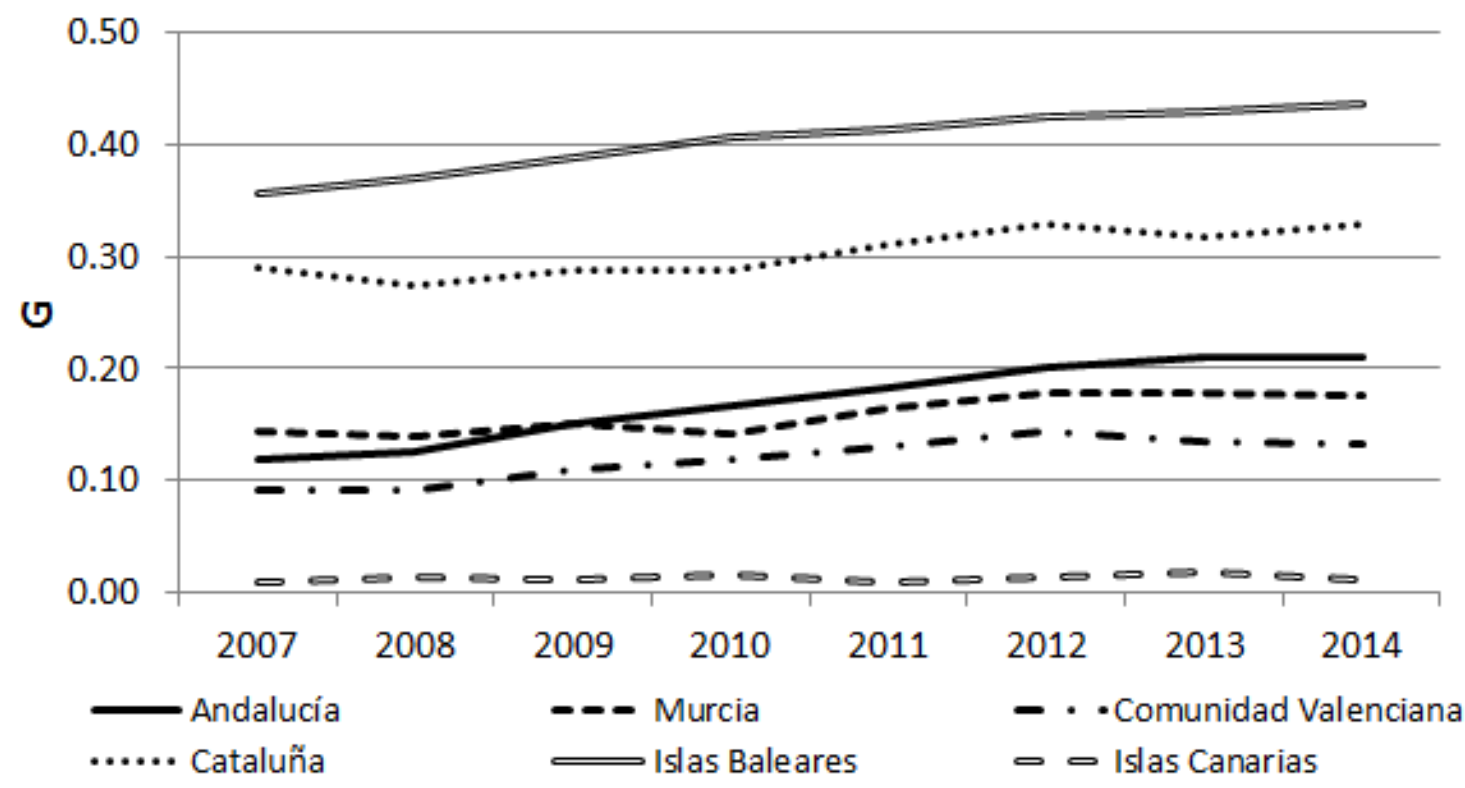

Figure 9 Seasonal concentration of employment in 3- and 4-star hotel segment (Gini index)

Figure 9 shows an increasing trend in the level of the Gini indices for all regions. This phenomenon can be explained, at least partially, by the growth in seasonal concentration of demand, already mentioned above. Therefore, the policies and actions taken to mitigate the seasonality in employment in this sector have been insufficient due to the increasing magnitude of seasonal concentration in demand.

However, this does not mean that the programme has a negligible deseasonalising effect on employment. The volume of direct jobs generated by the IMSERSO programme in the low season is highly relevant in almost all regions, such that it unequivocally helps to maintain a certain level of employment outside of the summer season. Employment generated by the IMSERSO programme has a significant weight in the low season in Cataluña and Islas Baleares, since these regions have the highest degree of seasonal concentration, and so lose more jobs during the winter season. The case of Islas Canarias has peculiar characteristics, since its level of seasonal concentration is much smaller than the other regions, and also the period of the programme is broader, from November to June. 
With the data estimates for the last year (2014), we calculated the change in the annual Gini index of employment in 3- and 4-stars hotels attributable to the presence of job contracts generated or maintained by the IMSERSO programme. For this, the Gini indices of the monthly distribution of employment, excluding those generated by the IMSERSO programme $\left(\mathrm{G}^{\mathrm{WIT}}\right)$ and the observed Gini Indices (G) are shown in Fig 10. The horizontal difference with respect to the diagonal can serve as an indication of the impact that the demand generated by the IMSERSO trips produces on the measure of annual concentration of employment.

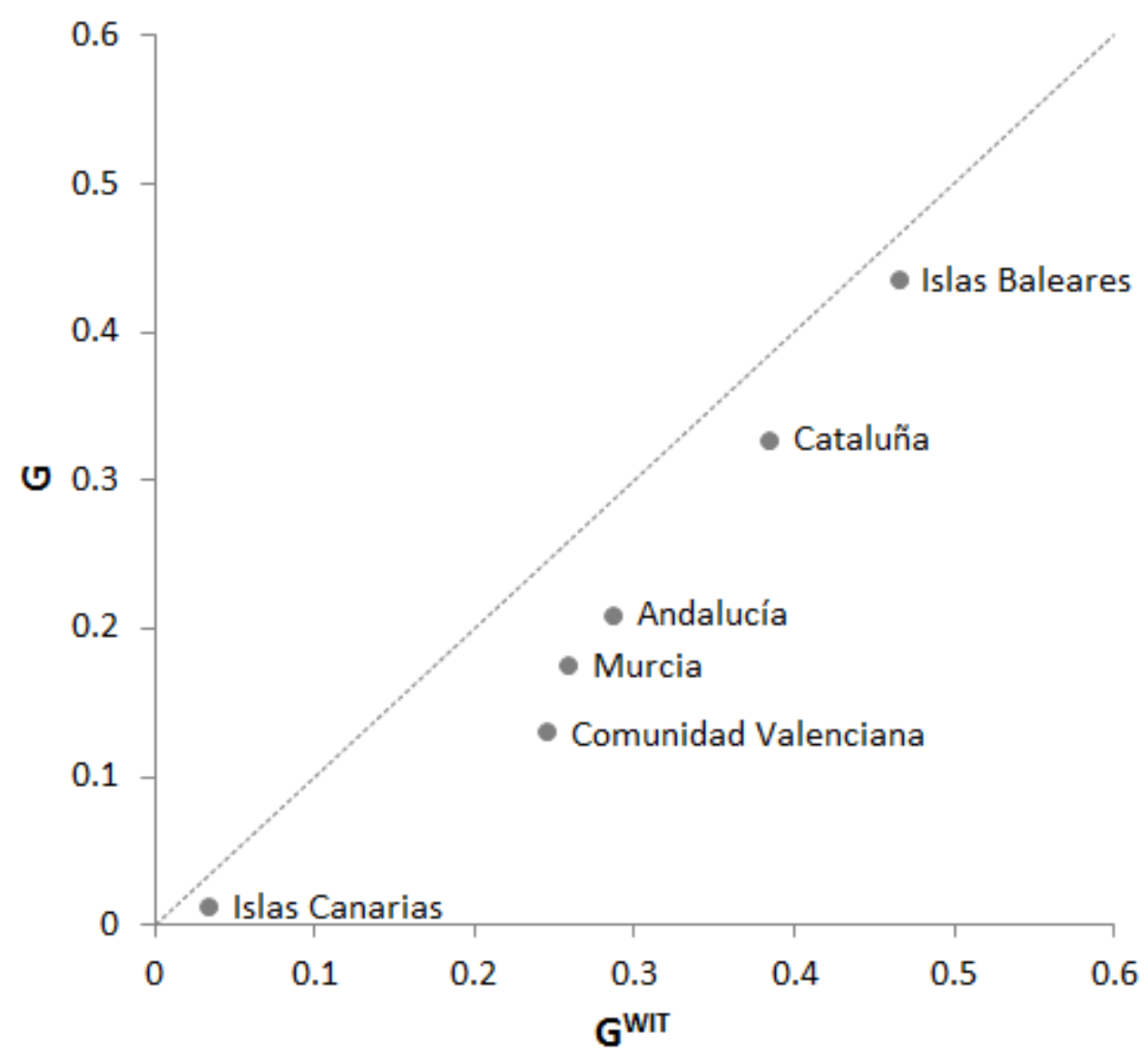

Figure 10 Seasonal concentration of employment: Gini index (2014)

Figure 10 shows that the greatest effect is found in the degree of seasonal concentration of employment by incorporating the jobs maintained or generated by the IMSERSO programme in the regions of Comunidad Valenciana, Murcia, Cataluña and Andalucía. Again, these results are parallel those obtained in the distribution of overnight stays, although with slight differences in the order of magnitude.

\section{Conclusions}

Seasonality in tourism activity is a perennial problem in the tourism system and a challenge for sustainability across all three pillars; environment, society and economy. This study adds to the debates concerning the achievement of sustainable tourism in the context of mass urbanised Spanish coastal destinations. Such destinations require more even flows of tourist demand to sustain employment and quality of life for residents, to generate tax income that can be invested 
in continuous improvements in infrastructure and environment, and which provides a model for a vibrant tourism economy in the Mediterranean region for the future. Social tourism offers one solution to create a more even spread of demand, whilst contributing to quality of life benefits for tourists and economic sustainability of resorts and regions. This study contributes to the debates in sustainable tourism providing evidence on the economic sustainability issues which are rarely tackled in the literature. Furthermore, it provides tangible evidence on seasonality factors as a contributor to sustainable tourism, something which has only implicitly been acknowledged in the literature previously. This research also contributes important evidence to support the idea that social tourism can contribute to economic sustainability through combatting seasonal imbalances in demand for the first time. Social tourism can therefore contribute to policy and strategy initiatives in sustainable tourism, particularly in highly seasonal destinations/markets.

One of the main objectives of social tourism in Spain is to generate greater hotel occupancy in times of low activity, and our results confirm that this objective is met. This in turn has a major impact on the whole sector (transport, travel agencies, hospitality etc.), improving economic activity in tourist areas. Social tourism can therefore lead to additional important social benefits such as preventing the closure of tourist establishments by providing a greater entertainment during the low season in coastal resorts. This leads to greater sustainability of the destinations, helping maintain economic activity and employment in the low season, favouring medium and long-term profitability. Furthermore, this could contribute to improved quality of life for local residents, and a more vibrant local economy in the low season could also lead to the development of additional markets. This is in addition to the social objective of increasing the quality of life of elderly people, enabling them experience new places, perform specific tourism activities and thus enrich their leisure time.

Our results have shown however, that despite these positive outcomes, the problems of seasonal concentration have not been resolved in all of the coastal areas studied. The extremely high seasonal concentration levels were observed in five of the six regions studied, both in the distribution of overnight stays and employment; and indeed was found to be increasing in almost all the destinations. In fact, with the exception of the Islas Canarias, all regions show an increasing seasonal concentration of demand in 3- and four-stars hotels along the period observed, despite the existence of the social tourism programme.

In each of the regions, the IMSERSO programme has a different seasonal impact, depending on several factors: (1) the degree of seasonal concentration observed, (2) the weight of domestic tourism, and (3) the seasonal distribution presented in the other segments of demand. Thus, the effect on the seasonality of demand generated by the IMSERSO is affected not only by the specific characteristics of their design and monthly distribution, but also by the structure of demand in host regions. For example, the volume and distribution of international demand significantly affects the potential deseasonalising effect of the IMSERSO trips. Thus, to a greater or lesser extent it is clear that this programme has a clear effect but of a variable magnitude depending on the region and the overall level of demand. 
One of the most important findings is that the seasonal concentration issues are exacerbated by the relative reduction in the volume of demand generated by the IMSERSO programme due to the effects of the budget cuts caused by the global financial crisis. That is, taking into account the important deseasonalising effect of this programme, the relative reduction of the IMSERSO activity over the eight years studied, together with the increased seasonal concentration of the international segment in some regions has contributed to a greater seasonal concentration in overnight stays and employment.

Accepting the above, social tourism programmes should be promoted as a way to reduce seasonality, in five of the six regions studied. This is confirmed by the analysis of RME which indicated that in all regions an increase in this segment would have a marginal negative shortterm effect on the index of seasonal concentration. Although the magnitude of this effect is different depending on the region, it is especially effective in Andalucía, Murcia and Comunidad Valenciana.

Concerning the policy recommendations, the proposed methodology and the results of this study can be very useful for the design of policies against seasonality. As has been found, the reduction in the number of places offered by IMSERSO in recent years has worsened the problem of seasonality, and in addition, there are more applications than places offered. Although the IMSERSO could opt to offer more places, it would be useful to take into account the results of this study - as the ERM by regions - for both the design of counter-seasonal policies, and for planning the number of extra places to be offered from both national and regional perspective. Furthermore, given that the IMSERSO trips can serve as a tool against seasonal concentration, and providing additional socio-economic benefits for destination regions, the possibility of extending these types of initiatives can be considered. One option would be to extend the offer to pre-retirees, the over 55's, who might be 'empty-nesters', and have more flexibility in work patterns. Another target group may be people with disabilities and their families and carers, and unemployed or low-income groups. An extension of the programme to these groups would expand the social impact of the IMSERSO activity.

In addition, the IMSERO programme has been recognised internationally as good practice in social tourism and various countries have expressed an interest in this programme. There have been efforts to expand the programme internationally, but with limited success, such as the EST mentioned previously, aimed at European senior tourists in bilateral transnational mobility exchange. The programme suffered cutbacks in funding following the 2008 global financial crisis, and the extent that it can remain sustainable into the long term is dependent on the participation and funding commitment of different countries. Due to the lack of monthly data on overnight stays produced through the EST programme, the measurement of its specific deseasonalising impact was not possible. This may be a future line of work to expand this analysis. Of course, the benefits of international social tourism may benefit Spain and other Southern Mediterranean European countries but this may counteract the arguments for social tourism as sustainable tourism in the generating countries. Certainly, the contribution of domestic programmes to economic sustainability can be assured.

\section{Notes}


${ }^{1}$ The coastal destinations analyzed correspond to those consolidated by the IMSERSO trips (IMSERSO, 2015b): Andalucía: Almería (Costa de Almería), Granada (Costa Tropical), Huelva (Costa de la Luz de Huelva) and Málaga (Costa del Sol). Murcia: Murcia (Costa Cálida). Comunidad Valenciana: Alicante (Costa Blanca), Castellón (Costa Azahar) and Valencia (Costa de Valencia). Cataluña: Barcelona (Costa de Barcelona, Garraf and Maresme), Gerona (Costa Brava) and Tarragona (Costa Dorada). Islas Baleares: Mallorca (Mallorca), Menorca (Menorca) and Ibiza (Ibiza and Formentera). Islas Canarias: Las Palmas (Gran Canaria) and Santa Cruz de Tenerife (Tenerife). The different coastal destinations where the IMSERSO trips take place, which are located in each of the coastal areas are disaggregated into the methodology of the Hotel Occupancy Survey "Encuesta de Ocupación Hotelera" (INE, 2014d).

Regions (bold); Provinces (regular); Coastal areas (italic).

${ }^{2}$ Andalucía: Cádiz (Costa de la Luz de Cádiz). Cataluña: Barcelona (Badalona, Barcelona, Hospitalet de Llobregat, Sant Adria de Besos and Santa Coloma de Gramenet). Islas Canarias: Las Palmas (Fuerteventura and Lanzarote), Santa Cruz de Tenerife (La Palma, La Gomera and El Hierro).

Regions (bold); Provinces (regular); Coastal areas (italic).

\section{Acknowledgments}

The authors acknowledge the collaboration of the IMSERSO "Instituto de Mayores y Servicios Sociales" in providing the raw data for this research. The authors also thank the "Ministerio de Educación" of the Spanish Government and the "Unversidad de Málaga" for their financial support.

\section{Notes on contributors}

Jose David Cisneros-Martinez received the $\mathrm{PhD}$ degree in tourism and is a researcher at the University of Málaga. He has conducted research stays at the University of Nottingham and the Universidad Nacional de General San Martín. He is the author of papers focusing on tourism seasonality published in journals as Current Issues in Tourism, and Tourism Management; and has presented research papers to several international conferences in tourism.

Scott McCabe is a professor of marketing and tourism at Nottingham University Business School. His research is focused on tourist experience and consumer behavior particularly on issues around social tourism. He is the author of Marketing Communications in Tourism and Hospitality, editor of the Routledge Handbook of Tourism Marketing and co-editor of Social Tourism in Europe. He has published widely on subjects such as the theoretical links between tourist experience and everyday life, and marketing communications.

Antonio Fernández-Morales is a professor at the University of Malaga in the Department of Statistics and Econometrics. His research has been published in journals as Annals of Tourism Research, Tourism Management, and Current Issues in Tourism; and is the author of several textbooks in Spanish about Statistical Methods for Tourism Analysis. His main research interests in the field of tourism are seasonality analysis and multivariate techniques applied to tourism analysis

\section{References}

Agarwal, S., \& Brunt, P. (2006). Social exclusion and English seaside resorts. Tourism Management, 27(4), 654-670. doi: 10.1016/j.tourman.2005.02.011 
Alén, E., Losada, N., \& Domínguez, T. (2016). The impact of ageing on the tourism industry: an approach to the senior tourist profile. Social Indicators Research, 127(1), 303-322. doi: 10.1007/s11205-015-0966-x

Alén, E., Nicolau, J. L., Losada, N., \& Domínguez, T. (2014). Determinant factors of senior tourists' length of stay. Annals of Tourism Research, 49, 19-32. doi:

10.1016/j.annals.2014.08.002

Allcock, J. B. (1994). Seasonality. In S. F. Witt, \& L. Moutinho (Eds.), Tourism marketing and management handbook (pp. 86-92). Cambridge: Prentice Hall.

Ashworth, J., \& Thomas, B. (1999). Patterns of seasonality in employment in tourism in the UK. Applied Economics Letter, 6(11), 735-739. doi: 10.1080/135048599352312

Ayuso S. (2003), Turismo Sostenible: ¿reto o ilusión?. Barcelona: Centre d'Estudis Ambientals.

BarOn, R. R. (1975). Seasonality in tourism: A guide to the analysis of seasonality and trends for policy making. London: Economics Intelligence Unit.

Baum, T., \& Lundtorp, S. (Eds.). (2001). Seasonality in tourism. Oxford: Pergamon, Elsevier. Baumgartner, C. (2011). Defining social tourism and its historical context. In S. McCabe, L. Minnaert, \& A. Diekmann (Eds.), Social tourism in Europe: Theory and practice (pp. 18-30). Bristol: Channel View Publications.

Butler, R. W. (1999). Sustainable Tourism: a state-of-the-art Review. Tourism Geographies, 1, 7-25. doi: 10.1080/14616689908721291

Butler, R. W. (2001). Seasonality in tourism: issues and implications. In T. Baum, \& S. Lundtorp (Eds.), Seasonality in Tourism (pp. 5e22). Oxford: Pergamon, Elsevier.

Butler, R.W., \& Mao, B. (1997). Seasonality in tourism: Problems and measurement. In P. E. Murphy (Ed.), Quality management in urban tourism (pp. 9-23). Chichester: Wiley.

Capó Parrilla, J., Riera Font, A., \& Rosselló Nadal, J. (2007). Accommodation determinants of seasonal patterns. Annals of Tourism Research, 34(2), 422-436.

doi:10.1016/j.annals.2006.10.002

Chen, S. C., \& Shoemaker, S. (2014). Age and cohort effects: The American senior tourism market. Annals of Tourism Research, 48, 58-75. doi: 10.1016/j.annals.2014.05.007

Cisneros-Martínez, J. D., \& Fernández-Morales, A. (2015). Cultural tourism as tourist segment for reducing seasonality in a coastal area: the case study of Andalusia. Current Issues in Tourism, 18(8), 765-784. doi: 10.1080/13683500.2013.861810

Cisneros-Martínez, J. D., \& Fernández-Morales, A. (2016). Concentración estacional de la demanda hotelera en Argentina. Revista de Estudios Regionales, 106, 197-221. Retrieved from http://www.revistaestudiosregionales.com/documentos/articulos/pdf-articulo-2499.pdf

Connell, J., Page, S. J., \& Meyer, D. (2015). Visitor attractions and events: responding to seasonality. Tourism Management, 46, 283-298. doi: 10.1016/j.tourman.2014.06.013

Coshall, J., Charlesworth, R., \& Page, S. J. (2015). Seasonality of overseas tourism demand in Scotland: a regional analysis. Regional Studies, 49(10), 1603-1620. doi:

10.1080/00343404.2013.859666 
Cuccia, T., \& Rizzo, I. (2011). Tourism seasonality in cultural destinations: empirical evidence from Sicily. Tourism Management, 32(3), 589-595. doi:

10.1016/j.tourman.2010.05.008

Diekmann, A., \& McCabe, S. (2011). Systems of social tourism in the European Union: a critical review. Current Issues in Tourism, 14(5), 417-430. doi:

10.1080/13683500.2011.568052

Diekmann, A., \& McCabe, S. (2013). Systems of social tourism in European Union: a critical review. In L. Minnaert, R. Maitland, \& G. Miller. Social tourism: Perspectives and potential (pp. 19-32). Routledge: Abingdon.

Duro, J. A. (2016). Seasonality of hotel demand in the main Spanish provinces: measurements and decomposition exercises. Tourism Management, 52, 52-63. doi:

10.1016/j.tourman.2015.06.013

Duro, J. A., \& Turrión-Prats (2015). Estacionalidad turística en Cataluña: descripción y análisis. Reuniones de Estudios Regionales, 1331. Retrieved from http://www.reunionesdeestudiosregionales.org/Reus2015/htdocs/pdf/p1331.pdf

eCalypso (2016). eCalypso - Tourism for all. Retrieved from http://ecalypso.eu/

European Commission (2016). Low season tourism - Projects. Retrieved from

http://ec.europa.eu/DocsRoom/documents?locale=en\&tags=calypso_project

European Economic and Social Committee (2006). Opinion of the economic and social committee on social tourism in Europe. Official Journal of the European Union, (2006/C 318/12). Retrieved form http://eur-lex.europa.eu/legal-

content/EN/TXT/?uri=CELEX\%3A52006IE1155

Eusébio, C., Carneiro, M. J., Kastenholz, E., \& Alvelos, H. (2016). The impact of social tourism for seniors on the economic development of tourism destinations. European Journal of Tourism Research, 12, 5-24. Retrieved from http://ejtr.vumk.eu/index.php/volume12/281v12125theimpactofsocialtourismforseniorsontheeconomicdevelopmentoftourismdestinations

Fernández-Morales, A., \& Mayorga-Toledano, M. C. (2008). Seasonal concentration of the hotel demand in Costa del Sol: a decomposition by nationalities. Tourism Management, 29(5), 940-949. doi: 10.1016/j.tourman.2007.11.003

Fernández-Morales, A., \& Cisneros-Martínez, J. D. (2015). Seasonal inequalities in visitor distribution in Argentina's tourism regions. E-Review of Tourism Research, 12(1/2), 115-126. Retrieved from http://ertr.tamu.edu/volume-12-issue-12-september-2015/volume-12-issue-12august-2015-applied-research-notes-2/

Fernández-Morales, A., \& Martín-Carrasco, Y. (2015). Concentración e impacto estacional del turismo de cruceros en Málaga. Revista de Estudios Regionales, 101, 43-70. Retrieved from http://www.revistaestudiosregionales.com/documentos/articulos/pdf-articulo-2449.pdf

Fernández-Morales, A., Cisneros-Martínez, J. D., \& McCabe, S. (2016). Seasonal concentration of tourism demand: Decomposition analysis and marketing implications. Tourism Management, 56, 172-190. doi: 10.1016/j.tourman.2016.04.004

Garcés Ferrer, J., Ferri Sanz, M., Durá Ferrandis, E., McCabe, S. \& Sánchez García, J. (2015). Social tourism and healthy aging. International Journal of Tourism Research, 18(4), 297-307. doi: 10.1002/jtr.2048 
Gil-Alana, L. A. (2010). International arrivals in the Canary Islands: Persistence, long memory, seasonality and other implicit dynamics. Tourism Economics, 16(2), 287-302. doi: $10.5367 / 000000010791305581$

Hall, D., \& Brown, F. (1996). Towards a welfare focus for tourism research. Progress in Tourism and Hospitality Research, 2(1), 41-57. doi: 10.1002/(SICI)10991603(199603)2:1<41::AID-PTH23>3.0.CO;2-6

Halpern, N. (2011). Measuring seasonal demand for Spanish airports: implications for counter-seasonal strategies. Research in Transportation Business \& Management, 1(1), 4754. doi: 10.1016/j.rtbm.2011.05.005

Higgins-Desbiolles, F. (2006). More than an "industry": The forgotten power of tourism as a social force. Tourism Management, 27(6), 1192-1208. doi: 10.1016/j.tourman.2005.05.020

Instituto de Mayores y Servicios Sociales (2014). Informe Annual 2014 [Adobe Digital Editions version]. Retrieved from:

http://imserso.es/InterPresent2/groups/imserso/documents/binario/informeanual2014.pdf

Instituto de Mayores y Servicios Sociales (2015a). Informe de Gestión del IMSERSO, ${ }^{\circ}$ Trimestre de 2015. Retrieved November 18, 2015, from Instituto de Mayores y Servicios Sociales (Madrid) database.

Instituto de Mayores y Servicios Sociales (2015b). Subdirección de Gestión. Retrieved November 18, 2015, from Instituto de Mayores y Servicios Sociales (Madrid) database.

Instituto de Mayores y Servicios Sociales (2016). Criterios de valoración 2016-2017 [Adobe Digital Editions versión]. Retrieved from

http://imserso.es/InterPresent2/groups/imserso/documents/binario/criteriosvaloracion1617.pdf

Instituto Nacional de Estadística (2010). Proyección de la población de España a largo plazo, 2009-2049 - Notas de Prensa [Adobe Digital Editions versión]. Retrieved from http://www.ine.es/prensa/np587.pdf,

Instituto Nacional de Estadística (2014a). Cuenta satélite del turismo de España [Dataset] Retrieved June 24, 2016, from

http://www.ine.es/jaxi/menu.do?type=pcaxis $\&$ path $=\% 2 F t 35 \% 2 F p 011 \&$ file=inebase $\& \mathrm{~L}=0$

Instituto Nacional de Estadística (2014b). Encuesta de Ocupación Hotelera - Viajeros y pernoctaciones por zonas turísticas [Dataset] Retrieved January 15, 2016, from:

http://www.ine.es/jaxiT3/Tabla.htm?t=2039\&L=0

Instituto Nacional de Estadística (2014c). Encuesta de Ocupación Hotelera - Personal ocupado por zonas turísticas [Dataset] Retrieved January 12, 2016, from:

http://www.ine.es/jaxi/Tabla.htm?path=/t11/e162eoh/a2014/10/\&file=03of016.px\&L=0,

Instituto Nacional de Estadística (2014d). Encuesta de Ocupación Hotelera - Metodología [Adobe Digital Editions version]. Retrieved from

http://www.ine.es/daco/daco42/ocuphotel/notaeoh_14.pdf

Kim, H., Woo, E., \& Uysal, M. (2015). Tourism experience and quality of life among elderly tourists. Tourism Management, 46, 465-476. doi: 10.1016/j.tourman.2014.08.002

Koenig-Lewis, N., \& Bischoff, E. E. (2003). Seasonality of tourism in Wales: a comparative analysis. Tourism Economics, 9, 229-254. doi: 10.5367/000000003101298376 
Koenig-Lewis, N., \& Bischoff, E. E. (2005). Seasonality research: the state of the art. International Journal of Tourism Research, 7(4-5), 201-219. doi: 10.1002/jtr.531

Lerman, R. I., \& Yitzhaki, S. (1985). Income inequality effects by income source: a new approach and applications to the United States. The Review of Economic and Statistics, 67(1), 151-156. doi: 10.2307/1928447

López Bonilla, J. M., \& López Bonilla, L. M. (2007). Variabilidad estacional del mercado tur1'stico en Andalucía. Estudios y Perspectivas en Turismo, 16(2), 150-172. Retrieved from http://www. estudiosenturismo.com.ar/

Martín Martín, J. M., Jiménez Aguilera, J. D., \& Molina Moreno, V. (2014). Impacts of seasonality on environmental sustainability in the tourism sector based on destination type: an application to Spain's Andalusia region. Tourism Economics, 20(1), 123-142. doi: $10.5367 /$ te. 2013.0256

McCabe, S., \& Johnson, S. (2013). The happiness factor in tourism: subjective well-being and social tourism. Annals of Tourism Research, 41, 42-65. doi: 10.1016/j.annals.2012.12.001

Minnaert, L., Diekmann, A., \& McCabe, S. (2012). Defining social tourism and its historical context. In S. McCabe, L. Minnaert, \& A. Diekmann (Eds.), Social tourism in Europe: Theory and practice (pp. 18-30). Bristol: Channel View Publications.

Minnaert, L., Maitland, R., \& Miller, G. (2006). Social tourism and its ethical foundations. Tourism Culture \& Comunication, 7(1), 7-17. doi: 10.3727/109830406778493533

Minnaert, L., Maitland, R., \& Miller, G. (2009). Tourism and social policy: the value of social tourism. Annals of Tourism Research, 36(2), 316-334. doi: 10.1016/j.annals.2009.01.002

Minnaert, L., Maitland, R., \& Miller, G. (2011). What is social tourism?. Current Issues in Tourism, 14(5), 403-415. doi: 10.1080/13683500.2011.568051

Nuñez, I., \& Baison, G. (2007). Turismo social para personas mayores: estudio comparativo entre países, Comentarios de la Seguridad Social, 15, 213-226. Retrieved from http://www.bps.gub.uy/bps/file/1690/1/turismo-social-para-personas-mayores.-estudiocomparativo-entra-paises.--i.-nunez-y-g.-baison.pdf

Podder, N. (1993). The disaggregation of the Gini coefficient by factor components and its applications to Australia. Review of Income and Wealth, 39(1), 51-61. doi: 10.1111/j.14754991.1993.tb00437.x

Podder, N., \& S. Chatterjee (2002). Sharing the national cake in post reform New Zealand: income inequality trends in terms of income sources. Journal of Public Economics, 86, 1-27. doi: 10.1016/S0047-2727(01)00117-7

PricewaterhouseCoopers (2012). Evaluación del impacto del programa de vacaciones para mayores del IMSERSO (Report 2012). Retrieved from http://www.mundosenior.es/st/portal/page/portal/MundoSenior/Produccion/Mundosenior/Estu dios-de-Impacto.html

Roselló, J., \& Sansó, A. (2017). Yearly, monthly and weekly seasonality of tourism demand: A decomposition analysis. Tourism Management, 60, 379-389). doi: 10.1016/j.tourman.2016.12.019

Saarinen, J. (2006). Traditions of sustainability in tourism studies. Annals of Tourism Research, 33(4), 1121-1140. doi: 10.1016/j.annals.2006.06.007 
Walton, J. K. (2013). 'Social tourism' in Britain: history and prospects. Journal of Policy Research in Tourism, Leisure and Events, 5(1), 46-6. doi: 10.1080/19407963.2012.703377

Yepes Piqueras, V. (2002). Estrategias y política turística de la Comunidad Valenciana: su incidencia en el litoral. Cuadernos de Turismo, 9, 165-173. Retrieved from

http://revistas.um.es/turismo/article/view/21901/21191

Yitzhaki, S., \& Schechtman, E. (2013). The Gini methodology. New York: Springer. 